\title{
Molecular phylogenetic evidence for a wide circumscription of a characteristic Irano-Turanian element: Acantholimon (Plumbaginaceae: Limonioideae)
}

\author{
FARIDEH MOHARREK ${ }^{1}$, SHAHROKH KAZEMPOUR-OSALOO ${ }^{1, *}$, MOSTAFA ASSADI $^{2}$ and \\ GONZALO NIETO FELINER ${ }^{3, *}$
}

\author{
${ }^{1}$ Department of Plant Biology, Faculty of Biological Sciences, Tarbiat Modares University, Tehran 14115- \\ 154, Iran \\ ${ }^{2}$ Department of Botany, Research Institute of Forests and Rangelands, Tehran 13185-116, Iran \\ ${ }^{3}$ Real Jardín Botánico, CSIC, Plaza de Murillo 2, Madrid, Spain
}

Received 19 November 2016; revised 8 April 2017; accepted for publication 21 April 2017

\begin{abstract}
Acantholimon is an important component of the subalpine steppe flora in the Irano-Turanian region and the second largest genus of Plumbaginaceae with c. 200 cushion-forming subshrubby species. Because the genus has been poorly represented in previous phylogenetic studies, questions regarding its monophyly, phylogenetic relationships and infrageneric classification have not been addressed in a solid evolutionary framework. We used sequences from the nuclear ribosomal internal transcribed spacers and the plastid $\operatorname{trn} Y^{(\mathrm{GUA})}-\operatorname{trn} T^{(\mathrm{GGU})}$ intergenic spacer for 197 accessions of Acantholimon and nine putatively closely related Asian genera in Limonioideae. Contrary to previous results, Bayesian, maximum likelihood and maximum parsimony analyses show that Acantholimon is not monophyletic unless its limits are extended to include species currently placed in eight of these Asian genera. As circumscribed, the new Acantholimon s.l. is sister to Goniolimon and includes the following genera: Bamiania, Bukiniczia, Chaetolimon, Cephalorhizum, Dictyolimon, Gladiolimon, Popoviolimon and Vassilczenkoa. Our phylogenetic analyses also challenge the existing classification at the generic and infrageneric levels. A maximum likelihood reconstruction of ancestral states for morphological characters illustrates the possible scenarios by which the cushion architecture combined with linear acuminate leaves, also present in other steppic Irano-Turanian elements, were acquired in this group of Plumbaginaceae. Our study shows the importance of extensive taxon sampling for phylogenetic reconstruction of species-rich lineages.
\end{abstract}

ADDITIONAL KEYWORDS: Irano-Turanian region - ITS - molecular phylogenetic analysis - morphological character evolution - plastid trnY-T.

\section{INTRODUCTION}

The caryophyllid family Plumbaginaceae has been the subject of a number of phylogenetic studies since it was first identified as the sister group of Polygonaceae in the large $r b c L$-based angiosperm phylogeny by Chase et al. (1993). The largest genus, Limonium Mill., and its most closely related genera have been largely clarified in several contributions (Lledó et al., 1998, 2000; Lledó, Erben \& Crespo, 2003, 2005). However, the available studies have not sampled an adequate representation

*Corresponding authors. E-mail: skosaloo@modares.ac.ir; nieto@rjb.csic.es of species from some of the 27 genera in the family (Kubitzki, 1993). As a consequence, there are gaps that mostly concern Asian genera and are partly concentrated around the large genus Acantholimon Boiss.

As traditionally defined, Acantholimon comprises cushion-forming subshrubs with linear acuminate leaves, occurring in mountainous regions across all elevation zones, although chiefly at mid and higher elevations, and growing in gravelly and stony soils or on exposed rocks. Although the genus is widely distributed from south-eastern Europe to south-western Asia and in Central Asia, western Tibet and eastern Tian Shan, its main centre of diversity is the Irano-Turanian region (Bunge, 1872; Mobayen, 1964; Linczevski, 1967; 
Kubitzki, 1993; Assadi, 2005, 2006; Doğan \& Akaydin, 2007; Doğan et al., 2011). The genus was first described by Boissier (1846), including 27 species, but the two available comprehensive taxonomic studies raised that number to 83 (Bunge, 1872) and 119 (Mobayen, 1964). An updated comprehensive taxonomic revision is lacking and a number of specific names, mostly geographically restricted, require taxonomic assessment. However, based on the regional taxonomic studies and general systematic conspectus, the number of species exceeds 200 (Kubitzki, 1993; HernándezLedesma et al., 2016). More recent regional reviews have confirmed that the highest concentration of species is in the Irano-Turanian region (e.g. Assadi, 2005). Specifically, of the 164 Acantholimon spp. recognized in Flora Iranica (Rechinger \& Schiman-Czeika, 1974), 84 were recorded from Iran and 75 from Afghanistan, with only six, nine and 11 species recorded from Pakistan, Turkmenistan and Iraq, respectively. The genus is also well represented in Central Asia, mainly in Kyrgyzstan (Linczevski, 1967), and reaches the Xinjiang region (Peng \& Kamelin, 1996). In the western part of the genus range, 37 (Yildirim \& Crespo, 2014 ) to 52 species (Doğan \& Akaydin, 2007) have been reported from Turkey and only one species occurs in Europe (Moore, 1972).

The uncertainties concerning the phylogenetic relationships in and around Acantholimon concern a small number of species that show morphological, ecological and distributional affinities with Acantholimon, but do not match its overall classical morphology. Based on differences in general habit, leaf morphology and anatomy, inflorescence structure and shape, these species were directly described as, or segregated into, ten genera (Linczevski, 1967, 1971, 1979, 1985; Rechinger \& Schiman-Czeika, 1974; Kubitzki, 1993). These genera encompass only 19 species, since six of them are monotypic (Bamiania Lincz., Bukiniczia Lincz., Ghaznianthus Lincz., Gladiolimon Mobayen, Popoviolimon Lincz., Vassilczenkoa Lincz.); Chaetolimon (Bunge) Lincz., Cephalorhizum Popov \& Korovin, Dictyolimon Rech.f. and Neogontscharovia Lincz. include two, four, four and three species, respectively. The most recent comprehensive taxonomic treatment of the family, in which these segregate genera are accepted, was declaredly elaborated ex officio (Kubitzki, 1993).

Regarding phylogenetic relationships, the only study that has tested the relationships of one of those genera, Popoviolimon (as Cephalorhizum turcomanicum Popov, the type species), against 50 species representing Acantholimon was inconclusive (Moharrek, Kazempour-Osaloo \& Assadi, 2014). Popoviolimon was placed in Acantholimon in a nuclear ribosomal DNA tree, but not in a maximum likelihood plastid DNA tree; and a Shimodaira-Hasegawa test of nuclear and combined matrices failed to reject the null hypothesis that Acantholimon was monophyletic excluding Popoviolimon. The study by Lledó et al. (2005), focusing on Limonium and relatives, included single representatives of Cephalorhizum, Dictyolimon and Acantholimon, and the three were recovered together in a single clade. Although these studies have provided some clues about phylogenetic relationships in this group, the status of most of these small genera is still unclear and their relationships are in need of revision.

In addition to the issue of circumscription of Acantholimon, its infrageneric classification also demands attention. Fifteen sections were recognized by Rechinger \& Schiman-Czeika (1974) and largely by other authors (Assadi, 2005; Doğan \& Akaydin, 2007), based mostly on scape length and morphology of leaves, bracts, calyx and petals. However, although a phenetic analysis of 52 Acantholimon spp. gave some support for the circumscription of the three sections occurring in Turkey (Doğan, Akaydin \& Çakarogullari, 2007), those sections are not diagnosed by synapomorphic morphological characters, but rather by a combination of non-exclusive characters (e.g. spike-like or capitate inflorescences, heteromorphic leaves), casting doubts on their naturalness. In fact, the above-mentioned phylogenetic analysis questioned the monophyly of those three sections (Moharrek et al., 2014). These are sections Acantholimon (section Staticopsis Boiss. in some previous works, e.g. Rechinger \& Schiman-Czeika, 1974; Bokhari \& Edmondson, 1982; Assadi, 2005; Doğan \& Akaydin, 2007; Oganesian, 2011), Armeriopsis Boiss. (section Acantholimon in the same previous works) and Tragacanthina Bunge. Changes in the names of the first two sections implemented here were needed because the genus Acantholimon was declared a nomen conservandum (ICBN 1972, Appendix III) with A. glumaceum (Jaub. \& Spach) Boiss., from section Staticopsis, as the type species. This was overlooked by subsequent authors (Rechinger \& Schiman-Czeika, 1974; Bokhari \& Edmondson, 1982; Assadi, 2005; Doğan \& Akaydin, 2007; Oganesian, 2011), who believed that the type species was A. bracteatum (Girard) Boiss. This confusion arose from the fact that Linczevski, who wrote the proposal to conserve Acantholimon, first suggested A. bracteatum (in Taxon 18: 340-341, 1969) and then suggested A. glumaceum (in Taxon 19: 949, 1970) as the type species to be attached to the conserved name.

In summary, like Limonium (e.g. Lledó et al., 2000, 2003, 2005), about ten genera that are suspected to be closely related to Acantholimon, based either on preliminary phylogenetic studies or on distribution, taxonomic history and morphological features, need to be subjected to critical review and phylogenetic analysis. To address the generic delimitation, infrageneric relationships and morphological evolution of one of the most 
representative and species-rich genera of the IranoTuranian region, we performed phylogenetic analyses of approximately two-thirds of all Acantholimon spp. based on nuclear ribosomal DNA internal transcribed spacers (nrDNA ITS) and the plastid $\operatorname{trn} Y^{(\mathrm{GUA})}-\operatorname{trn} T^{\mathrm{GGU})}$ intergenic spacer $(\operatorname{trn} Y-T)$ with the objectives of: (1) testing the monophyly of Acantholimon with respect to the genera that are suspected to be most closely related; (2) testing the monophyly of the current sections of Acantholimon; and (3) examining the match between selected morphological characters and taxonomy under an explicit evolutionary frame using maximum likelihood ancestral character state reconstruction. In other words, we aim to use the molecular phylogenetic hypothesis resulting from our analyses to examine the consistency, as potential synapomorphies, of some morphological characters that have been used to diagnose sections and the putative closely related genera.

\section{MATERIAL AND METHODS}

\section{SAMPLING}

In total, 222 accessions corresponding to 121 Acantholimon spp. were included in our analyses of nrDNA ITS, and a subset of the samples (172 accessions from 100 species) was included in our analyses of the $\operatorname{trn} Y-T$ region. Fourteen representatives of eight genera that based on the above arguments are hypothesized to be closely related to Acantholimon were also included in the analyses: Bamiania, Bukiniczia, Chaetolimon, Cephalorhizum, Dictyolimon, Gladiolimon, Popoviolimon and Vassilczenkoa. We were not able to sample material from two of the ten genera: Ghaznianthus and Neogontscharovia, from Afghanistan and Tadzhikistan, respectively. Our ingroup comprised Acantholimon and the other eight genera. Also, we have sampled Goniolimon Boiss., based on the study of Lledó et al. (2005), in which the only three species in our ingroup sampled came out as sister to a clade containing two Goniolimon spp. Our outgroup consisted of 24 species belonging to Armeria Willd., Limonium and Psylliostachys (Jaub. \& Spach) Nevski of subfamily Limonioideae (Staticoideae; cf. Reveal, 2012) and Dyerophytum Kuntze and Plumbago L. of Plumbaginoideae, in accordance with previous studies (Lledó et al., 1998, 2001, 2005; Moharrek et al., 2014). Our sampling effort was mostly focused on herbarium collections (E, FUMH, HWANRC, M, MA, MSB, SHBU, TARI, TMUH, W), due to the current difficulties for sampling in some of the regions, but we also obtained a small number of the samples from fresh silica-gel dried material. In addition to the newly generated nrDNA ITS (152) and $\operatorname{trn} Y-T$ (112) sequences, 70 nrDNA ITS and $60 \operatorname{trn} Y-T$ sequences from Moharrek et al. (2014) were also included in the analyses. Of the 15 sections recognized by Rechinger \& Schiman-Czeika (1974) in Acantholimon, only the monotypic section Bromeliopsis Rech.f. \& SchimanCzeika (A. rechingeri Freitag from Afghanistan) is missing; this species is considered to belong to another genus, Ghaznianthus, by both Linczevski (1979) and Kubitzki (1993). Our sampling design encompassed the major areas of occurrence of Acantholimon in its main centre of diversity, Iran and Afghanistan and some areas in the eastern Mediterranean, the Caucasus, Central Asia and Pakistan. Taxonomy largely follows Rechinger \& Schiman-Czeika (1974) for sectional and species levels. Additionally, some species accepted and/ or described by Assadi (2005), Doğan \& Akaydin (2007) and Oganesian (2011) were also considered. We created three primary datasets: (1) nrDNA ITS only, comprising 222 terminals; (2) trn $Y$-T only, with 172 terminals; and (3) a combined nrDNA ITS and $\operatorname{trn} Y-T$ dataset comprising 222 terminals, in which $\operatorname{trn} Y-T$ sequences that were not available, affecting 50 samples, were treated as missing data. All samples, with locality data, voucher information and GenBank accession numbers, are listed in the Supporting Information, Appendix S1.

\section{DNA EXTRACTION, AMPLIFICATION AND SEQUENCING}

DNA extractions were done using the $2 \times$ CTAB method (Doyle \& Doyle, 1987) and DNeasy Plant Mini Kit from Qiagen AG (Basel, Switzerland), following the manufacturer's instructions. The nrDNA ITS sequences were amplified with universal primers P1A and P4 (Fuertes Aguilar, Rosselló \& Nieto Feliner, 1999), except for some cases in which primers ITS5m (Sang, Crawford \& Stuessy, 1995) and ITS4 (White et al., 1990) were used. For the $\operatorname{trn} Y-T$ region, primers trnT and $\operatorname{trn} Y$ (Shaw et al., 2005) were used. PCRs contained 20-200 ng of template DNA, $10 \times$ or $5 \times$ PCR buffer, $1.5 \mathrm{mM} \mathrm{MgCl}_{2}, 1 \mathrm{mM}$ dNTPs, $0.4 \mathrm{mM}$ of each primer and $0.4 \mathrm{~mL}$ Taq (Promega, Madison, WI, USA). For samples from old herbarium specimens, amplifications were performed using ReadyTo-Go beads (Amersham Biosciences Europe GmbH, Cerdanyola del Vallès, Barcelona, Spain) with 10-500 ng template DNA, $0.2-0.8 \mathrm{mM}$ of each primer and $4 \%$ dimethyl sulphoxide or bovine serum albumin. PCR conditions for both regions followed Moharrek et al. (2014). Sequencing reactions were performed at Macrogen Inc. (Seoul, Korea) using the same PCR primers.

\section{ALIGNMENT, PAIRWISE DIVERSITY AND PHYLOGENETIC ANALYSES}

Sequences were edited using BioEdit version 7.0.9.0 (Hall, 1999) and aligned with the web-based version of MUSCLE (Edgar, 2004; at http://www.ebi.ac.uk/Tools/ msa/muscle/, last accessed 12 May 2017) under default 
parameters followed by manual adjustment. Gaps resulting from alignment were treated as missing data. Pairwise genetic distances between sequences were calculated using the maximum composite likelihood model with pairwise deletions and gamma-distributed among-site rate variation, as implemented in MEGA version 5 (Tamura et al., 2011). Phylogenetic relationships were assessed using maximum parsimony, maximum likelihood and Bayesian inference. Analyses were first performed separately on the nuclear and plastid matrices and afterwards, once the possibility of serious incongruences was discarded, also on combined matrices. Maximum parsimony analyses were performed with PAUP* version 4.0b10 (Swofford, 2002). The heuristic search option was selected using 1000 replications of random addition sequence with ACCTRAN optimization, ten trees held at each step and tree-bisectionreconnection branch swapping with MulTrees on and steepest descent off. Branch support was assessed by 1000 bootstrap replicates (MP BS; Felsenstein, 1985) with the same settings as in heuristic searches. The program MrModeltest version 2.3 (Nylander, 2004) in combination with PAUP* was used to select an appropriate substitution model for each data partition, i.e. ITS and $\operatorname{trnY}$-T. A general time reversible model of nucleotide substitution with gamma distributed rates and a proportion of invariable sites (GTR + I + G) was identified as the best model for the two datasets based on the Akaike information criterion (AIC) (Posada \& Buckley, 2004). Maximum likelihood analyses were performed using raxmlGUI version 1.3 (Silvestro \& Michalak, 2012). Bootstrap values for maximum likelihood (ML BS) were calculated using raxmlGUI based on 1000 replicates with one search replicate per bootstrap replicate. The program MrBayes version 3.2 (Ronquist et $a l ., 2012$ ), run on the CIPRES Science Gateway (Miller, Pfeiffer \& Schwartz, 2010) for some of the analyses, was used for the Bayesian inference. Two simultaneous analyses with eight Metropolis-coupled Markov chain Monte Carlo (MCMC) chains with incremental heating of 0.2 were run for 60 million generations sampled every 1000 generations. We verified convergence of parameter estimates and that effective sample sizes were $>200$ for all parameters using Tracer version 1.4 (Rambaut \& Drummond, 2007). Additionally, we assessed convergence of the topology and clade stability using the online program Are We There Yet (AWTY; Nylander et al., 2008). The first $25 \%$ of the trees were discarded as burn-in. Data remaining after discarding burn-in samples were used to generate a majority-rule consensus tree where the percentage of samples recovering any particular clade in the consensus tree represented the posterior probability (PP) of the clade. Tree visualization was carried out using TreeView version 1.6.6 (Page, 2001). To test the effect of missing data in resolution and node support, a combined dataset without the 50 samples lacking the $\operatorname{trn} Y$-T sequence was also analysed in MrBayes.

\section{TESTS OF MONOPHYLY}

Monophyly of a group can be questioned when its node does not have enough statistical support based on posterior probability $(\mathrm{PP}<0.95)$. However, when other estimates of branch support (MP BS and ML BS) are stronger than Bayesian inference, the putative group is supported by morphological data or we want to double check a previously obtained clade that conflicts with our present results, a comparison of marginal likelihood estimates between two models, one topologically constrained to include the clade to be tested and one topologically unconstrained, can be used to evaluate monophyly (Lartillot \& Philippe, 2006; Baeza, 2016). The idea is to assess how compromising is ignoring the possibility of a group that may have taxonomic implications. Here we test the monophyly of three groups that are potentially important because they group a large number of species, but have only moderate or low nodal support in the Acantholimon s.l. clade: (1) Clade $\mathrm{A}(\mathrm{PP}=0.83, \mathrm{ML} \mathrm{BS}=80, \mathrm{MP} \mathrm{BS}=79)$, recovered by nrDNA ITS and combined trees; (2) the clade comprising subclades $\mathrm{A} 2+\mathrm{A} 3(\mathrm{PP}=0.82, \mathrm{ML} \mathrm{BS}=88, \mathrm{MP}$ $\mathrm{BS}=80$ ), recovered by nrDNA ITS and combined trees; (3) subclade A3 ( $\mathrm{PP}=0.82, \mathrm{ML} \mathrm{BS}=98, \mathrm{MP} \mathrm{BS}=80)$, recovered by molecular (nrDNA ITS, trnY-T and combined trees) data and supported by morphological data (Figs 1,2). In addition, we tested the monophyly of Acantholimon in its traditional sense, which was not conclusively rejected in a previous study (Moharrek et al., 2014). For this, Acantholimon s.s. was constrained as a monophyletic group.

We used Bayes factors to compare the posterior odds of the inferred tree topology with those of Bayesian trees in which monophyly of the tested groups is forced. Constrained analyses were conducted in MrBayes using the same parameters as in the unconstrained runs except for an absolute prior of 1.00 and the command 'prset topologypr = constraint'. Using the 'sump' command in MrBayes, we sampled the stationary (post-burnin) posterior distribution to obtain the harmonic mean of tree likelihood values (following Nylander et al., 2004; Ronquist, Huelsenbeck $\&$ van der Mark, 2005). The predictive values of the constrained harmonic mean likelihood $\left(\mathrm{H}_{1}\right)$ were then compared with the original unconstrained likelihoods $\left(\mathrm{H}_{0}\right)$ using a Bayes factor comparison with the formula (Kass \& Raftery, 1995):

$$
\begin{aligned}
\mathrm{B}_{10}= & \text { harmonic mean Ln likelihood } \mathrm{H}_{1} \\
& \text { - harmonic mean Ln likelihood } \mathrm{H}_{0}
\end{aligned}
$$




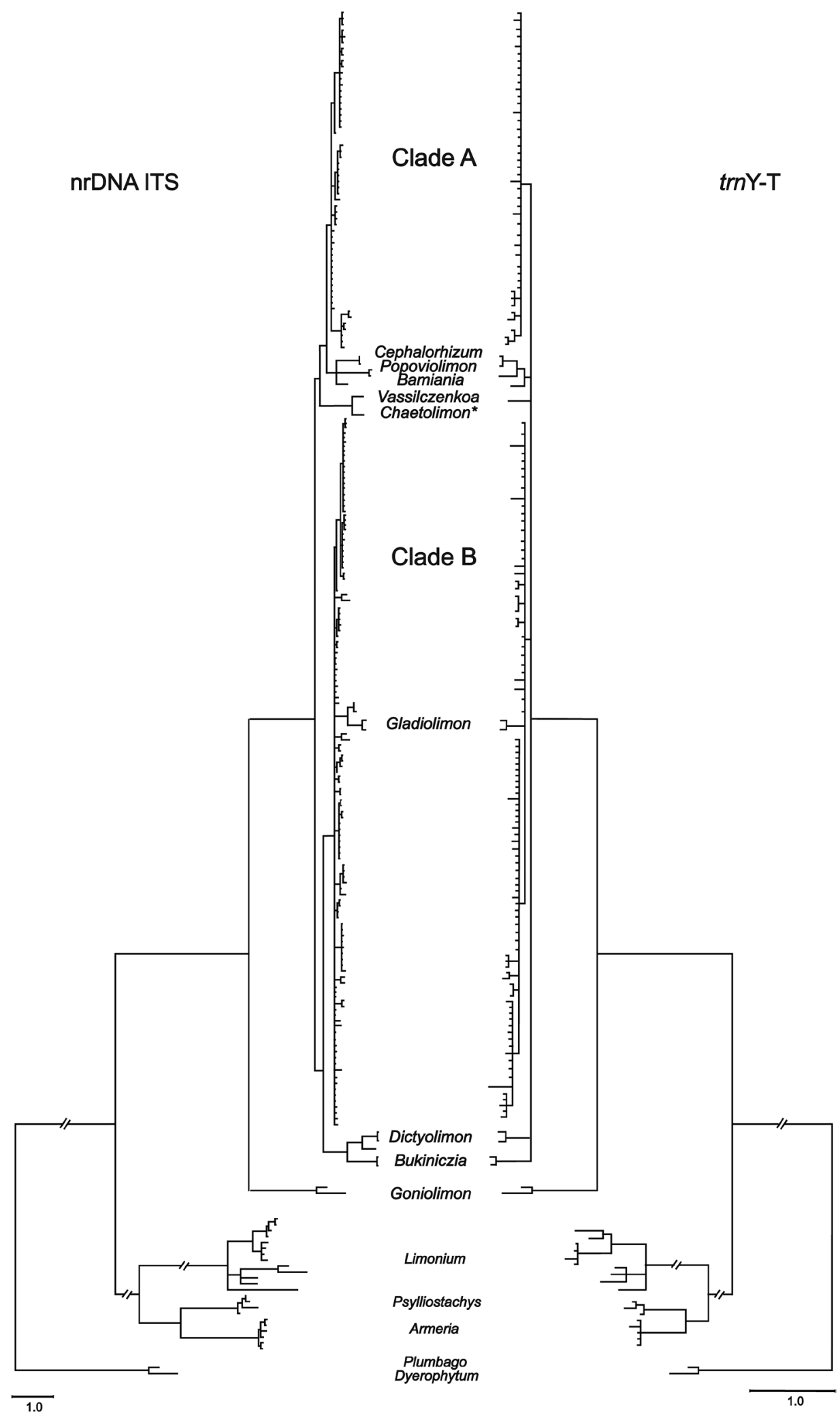

Figure 1. A comparison of the nrDNA ITS (left) and trnY-T (right) phylograms for Acantholimon and closely related genera (Bamiania, Bukiniczia, Chaetolimon, Cephalorhizum, Dictyolimon, Gladiolimon, Popoviolimon, Vassilczenkoa) obtained

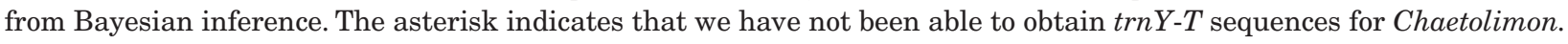




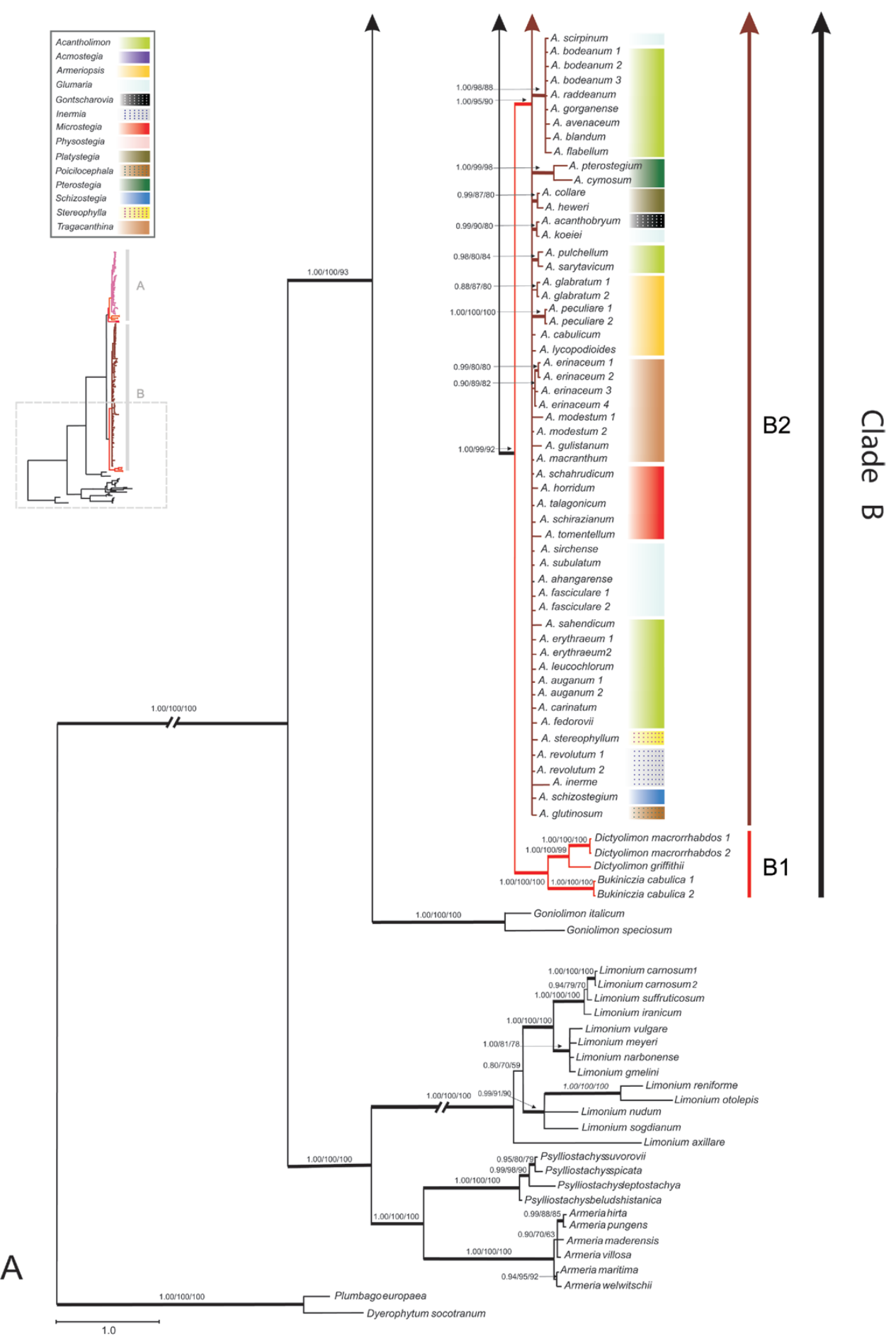

Figure 2. Bayesian 50\% majority rule consensus tree of Acantholimon and closely related genera (Bamiania, Bukiniczia, Chaetolimon, Cephalorhizum, Dictyolimon, Gladiolimon, Popoviolimon, Vassilczenkoa) based on a combined dataset of 222 sequences (195 ingroup, 27 outgroup) from nrDNA ITS and trn $Y$ - $T$ regions. Bayesian posterior probability (PP), maximum likelihood bootstrap (ML BS) and maximum parsimony bootstrap (MP BS) above the following thresholds are shown at the nodes: posterior probabilities $\geq 70$ and bootstrap values $\geq 50 \%$. Thickened lines indicate nodes with $P P$ support $\geq 0.95$. Colour-coded branches and vertical bars corresponding to labels A1, A2, A3, B1 and B2 indicate clades that are discussed in the text. Colour-coded rectangles indicate currently accepted sections in Acantholimon. 

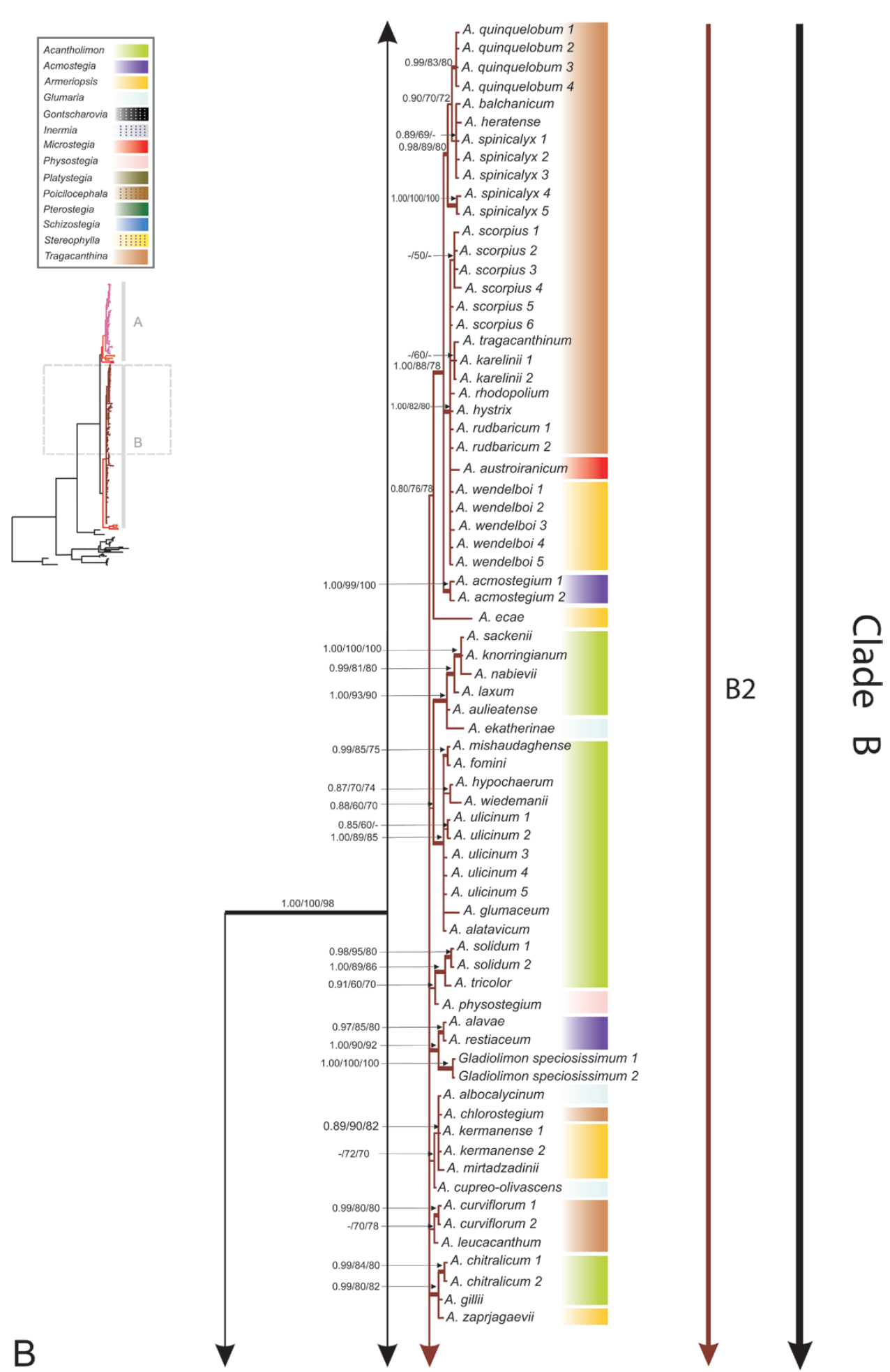

Figure 2. Continued

\section{ANCESTRAL CHARACTER STATE RECONSTRUCTION}

To examine the match between morphological evidence, upon which the current taxonomy is based, and the phylogenetic framework provided here, we reconstructed the character states for four selected discrete morphological characters. Character selection was made on the basis of relevance for diagnosing or supporting taxonomic groups, but avoiding 

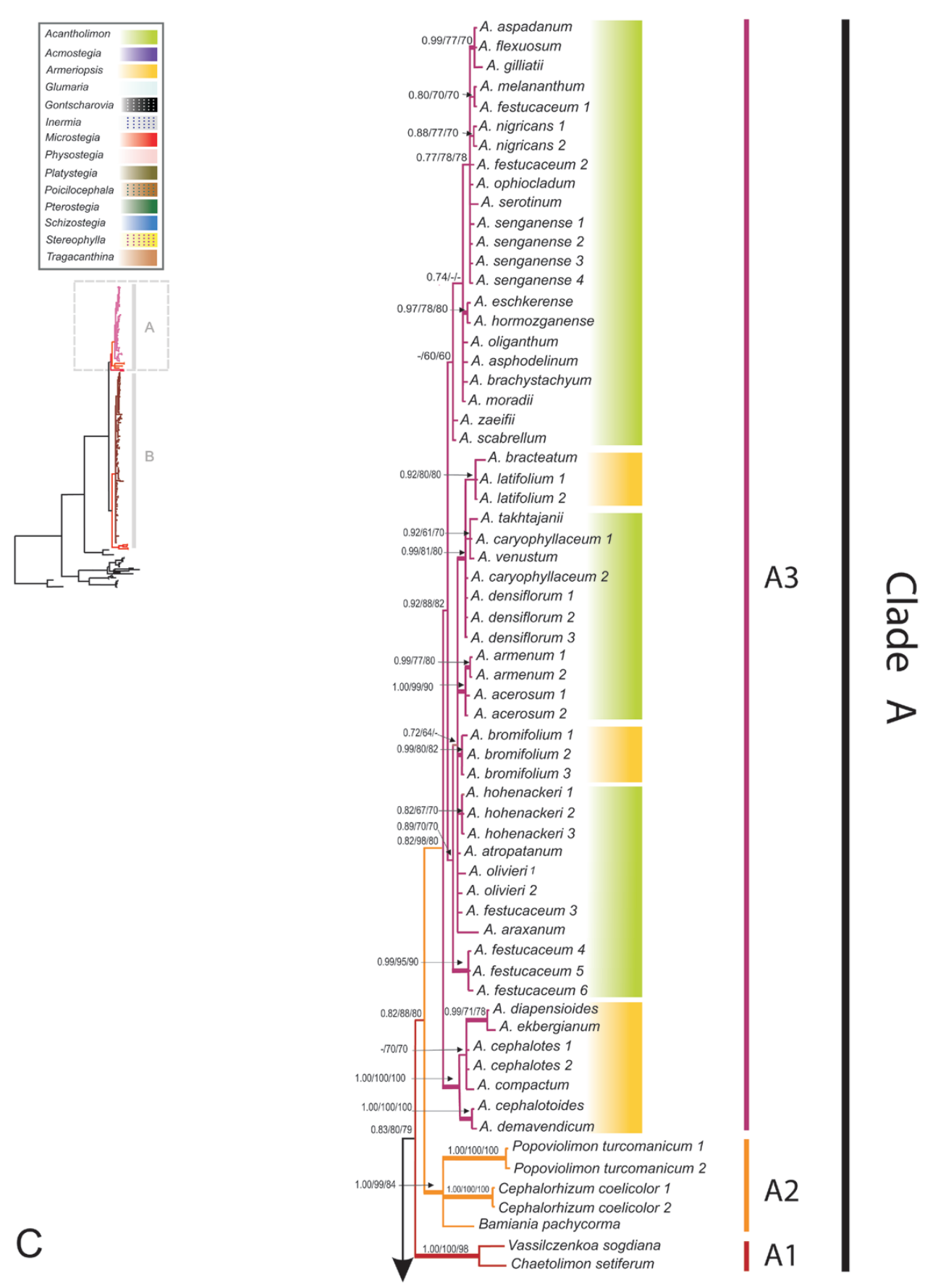

Figure 2. Continued

characters revealing high levels of homoplasy upon a first sight inspection of the phylogenetic tree. These include homomorphic vs. heteromorphic leaves, inflorescence architecture (spike-like, capitate, paniculate), number of bracts per spike, relative lengths of bracts and calyx, pubescence in organs including leaves, calyx or bracts. Four characters were finally analysed (Supporting Information, Appendix S2): habit (perennial herb with rosulate leaves vs. densely branched, caespitose to pulvinate subshrubs), leaf morphology (basically, flat spathulate vs. flat sublinear vs. linearacuminate, rigid), calyx shape (infundibular vs. tubular) and number of flowers per spikelet (one vs. two to five). Character coding was made based on taxonomic literature (Mobayen, 1964; Rechinger \& SchimanCzeika, 1974; Bokhari \& Edmondson, 1982; Assadi, 2005; Doğan \& Akaydin, 2007) and our own observations, opting for merging character states in doubtful 
cases. All characters were treated as unordered; three characters were coded as binary and one as a threestate character. To simplify the analysis and minimize establishing unlikely hypotheses of homology when comparing morphologies across distant species, we analysed only ingroup taxa and the resulting sister clade, Goniolimon, retaining one sample per species (Supporting Information, Table S1). Ancestral character states were reconstructed with the $R$ package APE (Paradis, Claude \& Strimmer, 2004; R Development Core Team, 2010), which allows a variety of analyses of phylogenetic trees and comparative data in a phylogenetic framework taking advantage of the many $R$ functions for statistics and graphics. Specifically, we used the ace (ancestral character estimation) function in APE, which is the most commonly used function for ancestral character estimation. We used a maximum likelihood tree (Supporting Information, Fig. S1) for two reasons: ace requires strictly bifurcating trees to reconstruct ancestral states and only maximum likelihood estimation is available for discrete characters (Pagel, 1994).

Three possible rate models were tested: (1) equalrates (ER) model, which implies one single rate; (2) symmetrical rates (SYM) model, in which forward and reverse transition rates are equal, but each characterstate combination can have a distinct rate; and (3) all rates different $(\mathrm{ARD})$ model, in which all rates are allowed to vary. Using the ace function, the likelihood of these three transition models was determined for each reconstruction (Supporting Information, Appendix S3).
The output for the ER model matches that of the SYM model for the three binary character states because for binary characters, unlike multistate, the ER and the SYM models are identical. For a three-state character, ER is a one-parameter model, SYM a three-parameter model and ARD a six-parameter model. For the four characters analysed, the ARD model gave the highest likelihood. However, it also includes more parameters that the ER and SYM models and it is well known that adding parameters to a model generally increases its likelihood. To determine whether the use of the most heavily parameterized model is appropriate, we performed a likelihood ratio test (LRT), which identified ARD as the best fit model in all reconstructions (Supporting Information, Appendix S3).

\section{RESULTS}

\section{SEQUENCE AND PHYLOGENETIC ANALYSES}

The Bayesian, maximum likelihood and parsimony analyses of the nrDNA ITS produced similar trees that differed only in nodal support. Statistics for the gene regions and trees and model choices are summarized in Table 1 . The trnY-T trees showed less resolution than the nrDNA ITS trees, in accordance with the lower number of potentially informative characters and the low sequence divergence values between the $\operatorname{trn} Y-T$ sequences (Supporting Information, Figs S2, S3). The average pairwise nucleotide diversity between Acantholimon s.s. and closely related genera was only

Table 1. Overall statistics and model selection for each DNA data partition for Acantholimon and related genera

\begin{tabular}{|c|c|c|c|}
\hline & nrDNA ITS & $\operatorname{trn} Y-T$ & nrDNA ITS $+\operatorname{trn} Y-T$ \\
\hline Number of sequences & 222 & 172 & 222 \\
\hline Number of characters & 711 & 1308 & 2019 \\
\hline GC content $(\%)$ & 53.2 & 34.7 & 43.7 \\
\hline Number of variable characters & 448 & 314 & 762 \\
\hline Number of potentially parsimony-informative characters & 365 & 198 & 563 \\
\hline $\begin{array}{l}\text { Number of potentially parsimony-informative characters in the } \\
\text { ingroup* }\end{array}$ & 169 & 57 & 226 \\
\hline Number of indels & 51 & 46 & 97 \\
\hline Number of indels in the ingroup* & 12 & 8 & 20 \\
\hline Average sequence divergence, all sequences $(\%)$ & 0.07 & 0.04 & 0.07 \\
\hline $\begin{array}{l}\text { Average sequence divergence, between Acantholimon s.s. and closely } \\
\text { related genera (ACRG) } \dagger(\%)\end{array}$ & 0.02 & 0.007 & 0.02 \\
\hline Number of most-parsimonious trees & 9233 & 1568 & 11678 \\
\hline Length of most-parsimonious trees & 1057 & 288 & 1399 \\
\hline Consistency index of most-parsimonious trees & 0.60 & 0.83 & 0.62 \\
\hline Retention index of most-parsimonious trees & 0.92 & 0.96 & 0.92 \\
\hline Evolutionary model selected (under AIC) & $\mathrm{GTR}+\mathrm{G}+\mathrm{I}$ & $\mathrm{GTR}+\mathrm{G}+\mathrm{I}$ & $\mathrm{GTR}+\mathrm{G}+\mathrm{I}$ \\
\hline
\end{tabular}

*Acantholimon, Bamiania, Bukiniczia, Chaetolimon, Cephalorhizum, Dictyolimon, Gladiolimon, Popoviolimon and Vassilczenkoa $\dagger$ Bamiania, Bukiniczia, Chaetolimon, Cephalorhizum, Dictyolimon, Gladiolimon, Popoviolimon and Vassilczenkoa. 
0.007 for the $\operatorname{trn} Y-T$ dataset (Table 1 ) and polytomies were present in basal and terminal nodes of the trees (Supporting Information, Fig. S3). However, no major incongruence was found between the topologies of the nrDNA ITS and $\operatorname{trn} Y-T$ trees, the only discrepancies consisting of a lack of resolution of internal nodes in the $\operatorname{trn} Y-T$ trees (Fig. 1; Supporting Information, Figs S2, S3). Therefore, the DNA matrices were combined into a single dataset. Phylogenetic analyses of the combined matrix based on maximum parsimony, maximum likelihood and Bayesian inference resulted in similar topologies with improved resolution and node support compared to the nrDNA ITS tree. From hereon, we describe and discuss the Bayesian tree from the combined matrix (Fig. 2).

Acantholimon in its current circumscription was found to be paraphyletic due to the the eight closely related genera (hereafter, ACRG) being nested in Acantholimon (Fig. 2). Acantholimon and these genera formed a well-supported clade $(\mathrm{PP}=1.00$, $\mathrm{ML} \mathrm{BS}=100, \mathrm{MP} \mathrm{BS}=98$ ), which we refer to as 'Acantholimon s.l.'. Goniolimon was recovered as sister to the Acantholimon s.l. clade ( $\mathrm{PP}=1.00, \mathrm{ML}$ $\mathrm{BS}=100, \mathrm{MP} \mathrm{BS}=93$ ). In the Acantholimon s.l. lineage, two major clades were recovered (A and $\mathrm{B}$ ) that contain five and three of the ACRG, respectively. Clade A includes only representatives of Acantholimon sections Acantholimon and Armeriopsis and of the ACRG $(\mathrm{PP}=0.83, \mathrm{ML} \mathrm{BS}=80, \mathrm{MP} \mathrm{BS}=79)$. Of these five genera, Chaetolimon and Vassilczenkoa form a subclade (A1; PP = 1.00, ML BS = 100, MP BS = 98) that is sister to the remainder of clade $\mathrm{A}$. The next diverging subclade is A2 containing Bamiania, Cephalorhizum and Popoviolimon forming a trichotomy (A2; PP $=1.00, \mathrm{ML}$ $\mathrm{BS}=99$, MP BS =84), which is in turn sister to subclade A3 with low support $(\mathrm{PP}=0.82, \mathrm{ML} \mathrm{BS}=88, \mathrm{MP}$ $\mathrm{BS}=80)$. The large clade $\mathrm{B}(\mathrm{PP}=1.00, \mathrm{ML} \mathrm{BS}=99$, MP BS =92) includes all the representatives of the medium-sized and small sections of Acantholimon (Acmostegia Bunge, Gontscharovia Lincz., Inermia Rech.f. \& Köie, Microstegia Bornm., Physostegia Rech.f. \& Schiman-Czeika, Platystegia Rech.f. \& SchimanCzeika, Poicilocephala Rech.f. \& Schiman-Czeika, Pterostegia Bunge, Schizostegia Rech.f. \& SchimanCzeika and Stereophylla Rech.f. \& Schiman-Czeika), representatives of the large sections Acantholimon, Armeriopsis, Glumaria Boiss. and Tragacanthina and three of the ACRG. Of these genera, Gladiolimon is deeply nested, forming a clade with two representatives of section Acmostegia ( $\mathrm{PP}=1.00, \mathrm{ML} \mathrm{BS}=90, \mathrm{MP}$ $\mathrm{BS}=92$ ); Bukiniczia and Dictyolimon form a subclade $(\mathrm{B} 1 ; \mathrm{PP}=1.00, \mathrm{ML} \mathrm{BS}=100, \mathrm{MP} \mathrm{BS}=100)$ that is sister to the remainder of clade B (subclade B2) (Fig. 2).

Internal resolution in Acantholimon s.s., i.e. clades A3 and B2, is rather poor and includes subclades with weak support. However, some small and large groups with strong support were also found across the two clades; these are discussed below. Regarding the monophyly of conspecific samples, of 38 species represented by multiple accessions, the samples in 17 of them were monophyletic, whereas samples of 16 formed polytomies with representatives of other species; samples of only five species were paraphyletic, although they fell close together in the tree (Fig. 2). Of those five species, only A. festucaceum (Jaub. \& Spach) Boiss. was affected by well-supported non-monophyly, with its six samples occurring in four different positions, although all in clade A3 (Fig. 2C).

The Bayesian 50\% majority rule consensus tree obtained from the combined dataset without missing data did not show changes in the composition of the major clades (A, A1, A2, A3, B, B1, B2). The only significant differences were the resolution of the trichotomy in A2, i.e. Bamiania sister to the other two genera, and the clustering of the sequences from the same species into monophyletic groups, e.g. for A. densiflorum Assadi due to the removal of samples with a high number of missing data. In addition, two new clades were recovered in B2 involving 21 and 13 species, although with no match with the current sections and weak support (results not shown).

\section{TESTS OF MONOPHYLY}

The comparison of marginal likelihood estimates from topologically constrained and unconstrained analyses for three groups in Acantholimon s.l. supports monophyly in the three cases (Table 2). The likelihood values of the unconstrained topologies $\left(\mathrm{H}_{0}\right)$ were lower (-17 196.74) than the alternative constrained topologies for clades A, A2+A3 and A3 (-16676.80, -16581.67 and -16557.71 , respectively). Therefore, the Bayes factors approach indicates that the constrained topologies are more likely, suggesting that even if the groups implied by the three tested clades have moderate support, they are not unrealistic. In contrast, when we tested the monophyly of Acantholimon s.s., i.e. excluding all the ACRG, the likelihood of the unconstrained topology $\left(\mathrm{H}_{0}\right)$ was higher $(-17196.74)$ than that of the alternative topology $\left(\mathrm{H}_{1}\right)$ in which the monophyly of Acantholimon s.s. was constrained (-18 865.66). Therefore, the Bayes factor approach indicates that the unconstrained topology is more likely and thus supports our finding that Acantholimon s.s. is not monophyletic.

\section{ANCESTRAL CHARACTER STATE RECONSTRUCTION}

The most likely habit for the most recent common ancestor of Acantholimon s.l. was reconstructed to be a pulvinate to densely branched caespitose subshrub with linear acuminate leaves, currently present in 
Table 2. Summary of Bayes factor comparisons of phylogenetic hypotheses with and without the monophyly of four groups of Acantholimon s.l. constrained (clades composition in Figure 2)

\begin{tabular}{|c|c|c|c|c|}
\hline $\begin{array}{l}\text { Tested constrained } \\
\text { hypothesis, } \mathrm{H}_{1}\end{array}$ & LnL: constrained $\left(\mathrm{H}_{1}\right)$ & LnL: unconstrained $\left(\mathrm{H}_{0}\right)$ & $\begin{array}{l}\text { Bayes factor } \\
{\left[2 \log _{\mathrm{e}}\left(\mathrm{B}_{10}\right)\right]}\end{array}$ & $\begin{array}{l}\text { Interpretation of evidence } \\
\text { (Kass \& Raftery, 1995) }\end{array}$ \\
\hline Clade A monophyletic & -16676.80 & -17196.74 & 1039.88 & Positive for $\mathrm{H}_{1}$ \\
\hline $\begin{array}{r}\text { Clades A2 + A3 } \\
\text { monophyletic }\end{array}$ & -16581.67 & -17196.74 & 1230.14 & Positive for $\mathrm{H}_{1}$ \\
\hline $\begin{array}{l}\text { Subclade A3 } \\
\text { monophyletic }\end{array}$ & -16557.71 & -17196.74 & 1278.06 & Positive for $\mathrm{H}_{1}$ \\
\hline $\begin{array}{l}\text { Acantholimon s.s. } \\
\text { monophyletic }\end{array}$ & -18865.66 & -17196.74 & -3337.84 & Positive for $\mathrm{H}_{0}$ \\
\hline
\end{tabular}

Acantholimon s.s. (Fig. 3). The alternative habit, perennial herb with rosulate leaves, occurs in most of the nested genera (Bamiania, Bukiniczia, Cephalorhizum, Dictyolimon, Popoviolimon, Chaetolimon, Vassilczenkoa) and in Goniolimon

With regard to leaf morphology, flat spathulate leaves (or at least widest towards the distal half), frequently slightly fleshy and leathery when dry (state 1), are common in some of the ACRG and in Goniolimon, whereas in Acantholimon s.s. leaves are linear or sublinear, acuminate, rigid and frequently triquetrous (state 3), except for A. inerme Rech.f. \& Köie and A. revolutum Rech.f. \& Köie (of section Inermia), which with Chaetolimon and Vassilczenkoa share sublinear to linear-oblanceolate, soft leaves (state 2; Fig. 3). The earliest diverging nodes in Acantholimon s.l. are inferred to have had state 3 for this character.

Our results indicate that the most recent common ancestor of Acantholimon s.l. most probably had an infundibular calyx (state 1; Fig. 4). This character state is maintained through the backbone nodes along branches leading to most of the clades containing species traditionally assigned to Acantholimon. The tubular calyx (state 2) occurs in a few species of Acantholimon s.s. and among portions of the ACRG (Bukiniczia, Chaetolimon, Gladiolimon and Vassilczenkoa) (Fig. 4). Regarding the number of flowers per spikelet, the likelihood scores at the backbone nodes of Acantholimon s.l. are virtually the same for both character states (Supporting Information, Fig. S4).

\section{DISCUSSION}

The monophyly of Acantholimon as traditionally circumscribed could not be confirmed nor rejected in a previous phylogenetic study based on a sampling $c$. $30 \%$ the size of the present one and including only one of the ACRG (Moharrek et al., 2014). In that study, Popoviolimon was placed in Acantholimon in an nrDNA tree, but not in a maximum likelihood plastid
DNA tree. A Shimodaira-Hasegawa test of nuclear and combined matrices failed to reject the null hypothesis that Acantholimon was monophyletic without including Popoviolimon. The present phylogenetic study, the most comprehensive for the genus Acantholimon conducted to date and the first to sample eight different ACRG in addition to Goniolimon, leads to two main conclusions. First, Acantholimon s.s. as currently circumscribed (Linczevski, 1971; Rechinger \& SchimanCzeika, 1974; Kubitzki, 1993) is not monophyletic. A monophyletic and well-supported Acantholimon s.l. includes Acantholimon s.s. and the ACRG Bamiania, Bukiniczia, Chaetolimon, Cephalorhizum,Dictyolimon, Gladiolimon, Popoviolimon and Vassilczenkoa. This result is not totally unexpected since three of the eight genera and more than half of the species represented in them were initially described under Acantholimon and later segregated on the basis of morphological characters such as habit and leaf morphology (Bunge, 1872; Mobayen, 1964; Linczevski, 1967, 1971, 1979; Rechinger \& Schiman-Czeika, 1974; Kubitzki, 1993).

The second main finding is that there are two distinct lineages, in which the species of Acantholimon s.s. are placed (clades A and B; Fig. 2), showing a poor match with the current taxonomic arrangement and the morphological characters on which this arrangement was based (see the sections on infrageneric classification and evolution of morphological characters below). These two lineages are supported by independent analyses of nrDNA and partly by plastid DNA data and in agreement with the above mentioned previous study based on a more restricted taxon sampling (Moharrek et al., 2014). Congruence between two molecular trees from differently inherited and evolving regions is a good indication that those trees are a fair representation of the organismal-level phylogenetic pattern of relationships (Nieto Feliner \& Rosselló, 2007). There is no clear taxonomic pattern associated with clades $\mathrm{A}$ and $\mathrm{B}$ beyond the smaller representation of sections in clade A. However, there is some geographical pattern since most species in clade A occur in the western areas of the Irano-Turanian region, 

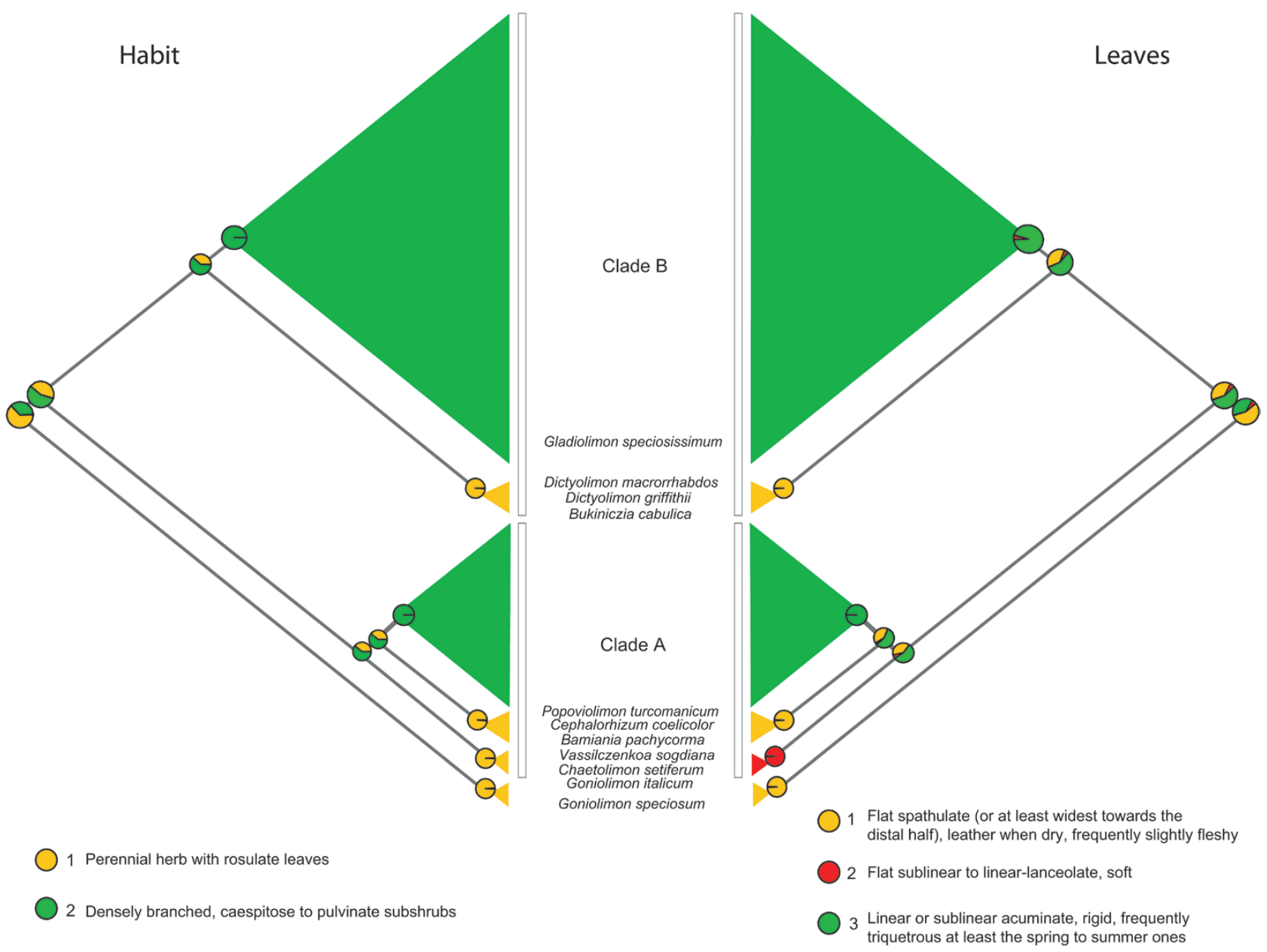

Figure 3. Morphological character evolution of habit (left) and leaves (right) optimized on a maximum likelihood tree obtained from a combined (nrDNA ITS and $\operatorname{trn} Y$-T) molecular dataset with one sample per species. Major clades are represented schematically with triangles proportional to their size; pie charts denote the likeliness of each character state being present at each node. A change from leaf character state 3 to 2 in A. inerme and A. revolutum is not reflected in this scheme.

i.e. eastern Mediterranean, Turkey, western Iran and western Caucasus. In contrast, eastern and western groups are found intermingled in clade B. Although this study is not focused on relationships beyond the Acantholimon s.l. clade, our phylogenetic analyses also indicate that Goniolimon is sister to the Acantholimon s.l. lineage (Figs 1, 2A).

Our results strongly challenge the current taxonomic circumscription of Acantholimon. To adequately represent the evolutionary relationships among the Asian lineages analysed here, the generic circumscription of Acantholimon should be extended to accommodate the nine ACRG, as explained below lineage by lineage. Our study also challenges the currently accepted infrageneric classification. However, compared to the generic circumscription, several facts urge caution before formally proposing sectional changes in the taxonomy of Acantholimon s.s. and thus we only discuss those changes informally below. These facts are the moderate or weak support for some branches in clades A and B (Fig. 2), the scarcity of morphological diagnostic characters supporting phylogenetic groups, although the morphological support for traditionally recognized sections is also weak (see below the infrageneric classification section), and the species sampling in this study, which although substantial is non-comprehensive.

Also, we hypothesize that weak to moderate support and resolution for some lineages could be due to a recent origin. However, not mutually exclusive alternative explanations may be also responsible or have contributed to such pattern. No doubt a broader sampling of the nuclear and plastid genomes would have generated more informative markers. In addition, the taxonomic studies independently developed in Turkey (Doğan \& Akaydin, 2007), Iran-Afghanistan (Rechinger \& Schiman-Czeika, 1974; Assadi, 2005), 


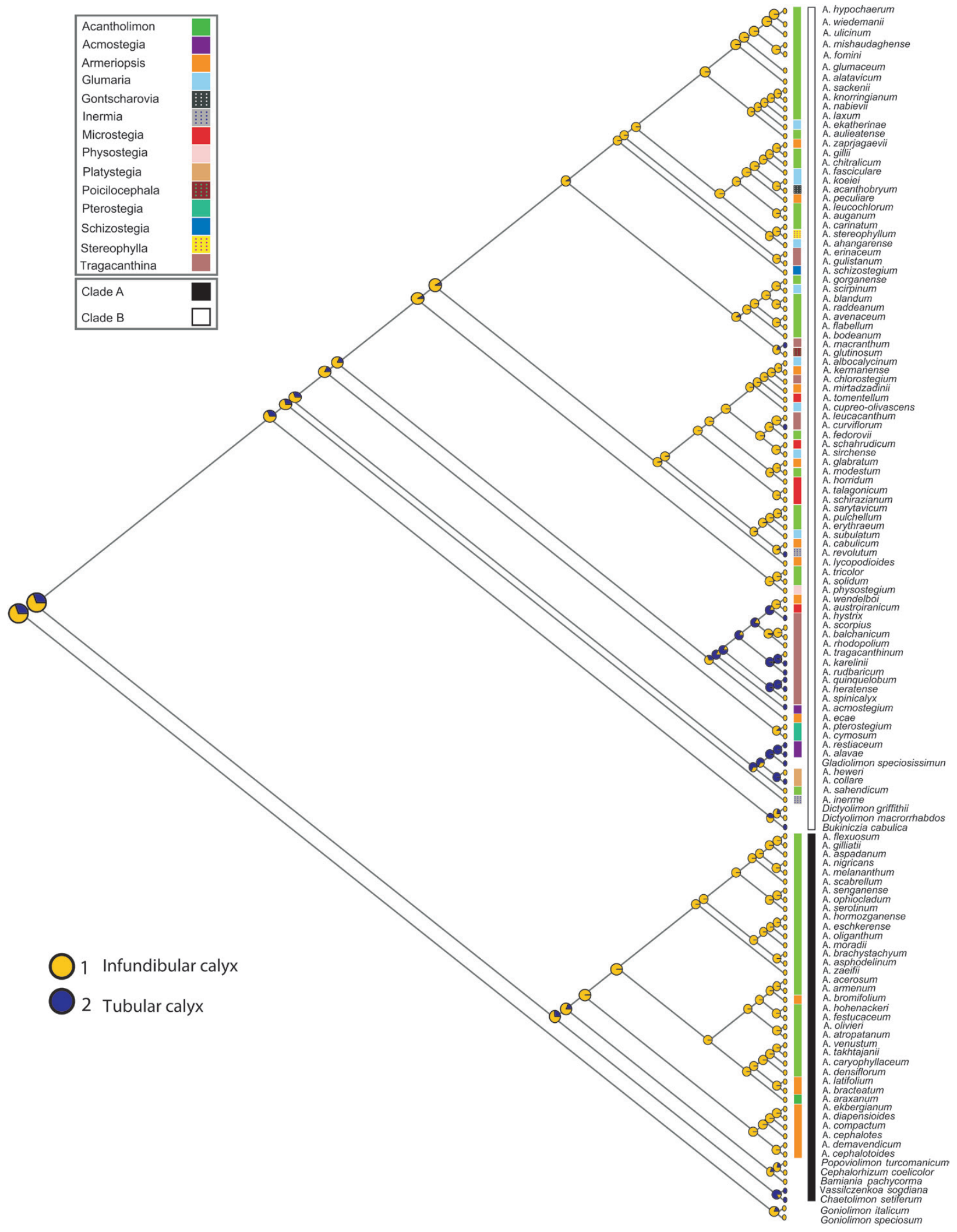

Figure 4. Morphological character evolution of calyx shape (infundibular vs. tubular) optimized on a maximum likelihood tree obtained from a combined (nrDNA ITS and $\operatorname{trn} Y-T)$ molecular dataset with one sample per species. 
former USSR territories (Linczevski, 1967) and eastern China (Peng \& Kamelin, 1996) demand a comprehensive updated revision. It is thus possible that the actual number of species is over-estimated and that such a synthetic revision will reduce the number of species, transforming some species that form polytomies in our trees into simple synonyms. Selective amplification of ITS copies when intragenomic polymorphisms occur could lead to some paralogy conflict (Álvarez \& Wendel, 2003). Also, lack of coalescence and the possibility of incomplete lineage sorting are not unlikely if diversification is recent, at least in some species with larger ranges and greater population sizes, e.g. A. acerosum (Willd.) Boiss., A. festucaceum, A. scorpius Boiss. and A. ulicinum Boiss. Another side effect of a recent diversification in which reproductive isolation is incomplete could be hybridization. Since there is no strong conflict between the plastid and nrDNA ITS trees, hints of the involvement of incomplete lineage sorting or hybridization could be explored in samples from the same species. However, our results are not indicative of a strong involvement of either phenomenon. We found no paraphyly among the sequences of 28 of the 38 species (74\%) for which there is intraspecific sampling and only in one case, A. festucaceum, did the placement of intraspecifc samples indicate well-supported non-monophyly (Fig. 2C), which might be due to hybridization (see below under section Acantholimon). Below we discuss generic and infrageneric levels independently.

\section{CIRCUMSCRIPTION OF ACANTHOLIMON}

By extending the boundaries of the genus Acantholimon we avoid naming a paraphyletic assemblage. Alternatives to a wide circumscription of Acantholimon, i.e. recognition of some or all of the ACRG at the generic level, would prevent us keeping Acantholimon s.s. species from the two main clades (A and $\mathrm{B}$ ) in a single genus. The geographical range, previous taxonomy and morphological and phylogenetic affinities of these ACRG are briefly commented on below together with the taxonomic implications of our analyses.

\section{Gladiolimon}

This genus is distributed in Afghanistan (Mobayen, 1964; Rechinger \& Schiman-Czeika, 1974), and its only species (Acantholimon speciosissimum Aitch. \& Hemsl.) was separated as an independent genus (Gladiolimon) by Mobayen (1964) based on its relatively large, flat leaves, two- or three-flowered spikelets and tubular calyx, but these characters match those in Acantholimon section Acmostegia. Its placement as sister to two representatives of section Acmostegia in the phylogenetic tree (Fig. 2B) confirms that the monotypic Gladiolimon should be included in Acantholimon, although this section cannot be maintained as such. Rechinger \& Schiman-Czeika (1974) also considered Gladiolimon part of Acantholimon, but they placed it in a different section (section Armeriopsis).

\section{Bukiniczia and Dictyolimon}

Bukiniczia (三Aeoniopsis Rech.f.) is distributed across Afghanistan and Pakistan (Kubitzki, 1993). This monotypic genus was created by Linczevski (1971) based on its ample paniculate inflorescences, tubular calyx and basal densely imbricate rosulate leaves. However, despite also being recognized as an independent genus by Kubitzki (1993), the inclusion of Bukiniczia cabulica (Boiss.) Lincz. in Acantholimon s.l. is strongly supported by our study. Dictyolimon is known to comprise four species from Afghanistan, Pakistan and India (Kashmir) (Rechinger \& SchimanCzeika, 1974; Kubitzki, 1993): D. macrorrhabdos (Boiss.) Rech.f., D. griffithii (Aitch. \& Hemsl.) Rech.f., D. gilesii (Hemsl.) Rech.f. and D. thomsonii (Clarke) Rech.f. They resemble Bukiniczia in habit and leaves, among other characters, but show emarginate petals and oblong-capitate stigmas compared to oblong stigmas in Bukiniczia (Rechinger \& Schiman-Czeika, 1974; Kubitzki, 1993). This is consistent with the phylogenetic trees, in which the clade formed by $D$. macrorrhabdos and $D$. griffithii is sister to the monotypic Bukiniczia with strong support (B1; Fig. 2A). Therefore, Dictyolimon and Bukiniczia could constitute a section under Acantholimon.

\section{Cephalorhizum, Bamiania and Popoviolimon}

The taxonomic history of these genera is intermingled because the single species of both Bamiania and Popoviolimon were segregated from Cephalorrhizum by Linczevski (1971). Cephalorrhizum, with four species [C. coelicolor (Rech.f.) Rech.f., C. micranthum Lincz., C. oopodum Popov \& Korovin and C. popovii Lincz.], is quite widespread inAfghanistan and parts of CentralAsia (Kubitzki, 1993), whereas Bamiania and Popovioliomon are endemic to Afghanistan and Turkmenistan, respectively (Rechinger \& Schiman-Czeika, 1974; Kubitzki, 1993). As explained above, Moharrek et al. (2014) questioned the independence of Popoviolimon based on nrDNA ITS evidence but not on $\operatorname{trn} Y$ - $T$ (see the beginning of the discussion). However, in our phylogenetic analyses Popoviolimon, Cephalorrhizum and Bamiania form a strongly supported lineage (A2; Fig. 2C) in clade A. Therefore, these three genera could constitute one section in Acantholimon s.l. 


\section{Chaetolimon and Vassilczenkoa}

Chaetolimon was separated from Acantholimon as an independent genus including three species [C. sogdianum Lincz., C. setiferum (Bunge) Lincz. and C. limbatum Lincz.] (Linczevski, 1967), one of which (C. sogdianum) was later segregated from Chaetolimon to create Vassilczenkoa (Linczevski, 1979). Chaetolimon setiferum and C. limbatum are distributed in Central Asia, across relatively low elevations in the mountains of the south-western Pamir-Alai, and western Tian Shan, whereas Vassilczenkoa sogdiana (Lincz.) Lincz. occurs in mountain ranges of Afghanistan and Tadzhikistan (Linczevski, 1967; Rechinger \& SchimanCzeika, 1974, Kubitzki 1993). Chaetolimon and Vassilczenkoa differ by the relative lengths of bracts and calyx (Linczevski, 1967), but they share habit and leaf morphology and both occur in apparently more developed soils, including meadows. In contrast, most species of Acantholimon s.s. grow in gravelly, stony or exposed rocky soils. In our phylogenetic trees, $C$. setiferum and $V$. sogdiana form a strongly supported clade (A1; Fig. 2C), which should be more appropriately treated as a section of Acantholimon s.l.

\section{INFRAGENERIC CLASSIFICATION OF ACANTHOLIMON}

With the exception of sections Platystegia and Pterostegia, with two species each, the remaining non-monotypic sections (Acantholimon, Acmostegia, Armeriopsis, Glumaria, Inermia, Microstegia and Tragacanthina) are not monophyletic according to our molecular phylogenetic results (Fig. 2). A brief discussion of the implications of our study in each of the currently accepted sections follows to identify the problems of the infrageneric taxonomic treatment.

\section{Section Pterostegia}

Including section Cymaria Bunge as recognized in the latest treatments (Mobayen, 1964; Rechinger \& Schiman-Czeika 1974; Assadi, 2005), it contains two species, A. pterostegium Bunge and A. cymosum Bunge, and is endemic to central and north-eastern Iran (Rechinger \& Schiman-Czeika, 1974; Assadi, 2005). Morphologically, this section is characterized by persistent homomorphic leaves, capitate or paniculate inflorescences, two- or three-flowered, two- to four-bracteate spikelets and an infundibular calyx, hairy within. Our phylogenetic analysis supports its recognition since the two species formed a strongly supported clade (Fig. 2A).

\section{Section Platystegia}

Like the previous section, this section contains two species (A. collare Köie \& Rech.f. and A. heweri Rech.f. \& Schiman-Czeika) and is consistent with the phylogenetic results (Fig. 2A). It is characterized by dimorphic leaves, capitate or lax inflorescence, one- to three-flowered, three- to six-bracteate spikelets and a tubular or infundibular calyx, glabrous within. The section is restricted to eastern Iran and north-western Afghanistan (Rechinger \& Schiman-Czeika, 1974; Assadi, 2005).

\section{Section Acmostegia}

This section contains three species, all endemic to Iran, and has unique characters in the genus, including heteromorphic bracts with the internal ones concealing the calyx. Other characters including homomorphic leaves, capitate inflorescences, one- or two-flowered, two- to four-bracteate spikelets and a tubular calyx, glabrous within, are not uncommon in other sections (Rechinger \& Schiman-Czeika, 1974; Assadi, 2005). Our study supports the close relationships between A. alavae Rech.f. \& Schiman-Czeika and A. restiaceum Bunge, which form a clade sister to Gladiolimon (Fig. 2B). However, the third species and type of the section, A. acmostegium Boiss., is well nested in a clade composed of members of sections Armeriopsis, Microstegia and Tragacanthina. Thus, our phylogenetic results do not support the recognition of this section including those three species.

\section{Section Gontscharovia}

Although originally described as including two species (A. mirandum Lincz. and A. mirum Lincz.) endemic to Central Asia (Linczevski, 1967), the section was later enlarged with two additional species from Afghanistan, A. saxifragifolium Rech.f. \& Köie and A. acanthobryum Rech.f. \& Schiman-Czeika (Rechinger \& SchimanCzeika, 1974), and subsequently recognized as an independent genus, Neogontscharovia (Linczevski, 1971), as followed by Kubitzki (1993). This section is characterized by sub-homomorphic, rigid but somewhat flattened leaves, two- to four-flowered, three- to sevenbracteate spikelets, small outer bracts and the calyx glabrous within. We have only sampled one species in this section, $A$. acanthobryum, which in our trees came out as sister to A. koeiei Rech.f. \& Schiman-Czeika of Afghanistan (section Glumaria) (Fig. 2A). Therefore, our limited sampling does not allow conclusions to be drawn regarding the status of section Gontscharovia.

\section{Section Inermia}

This includes two species endemic to Afghanistan, A. inerme and A. revolutum (Rechinger \& SchimanCzeika, 1974), which share unarmed soft leaves. In the inferred trees, $A$. inerme and $A$. revolutum did not form a monophyletic group, but since they are part of 
a large polytomy at the base of clade B2, their monophyly is not rejected (Fig. 2A).

\section{Sections Schizostegia, Poicilocephala and Stereophylla}

These three sections, established by Rechinger \& Schiman-Czeika (1974), are monotypic and endemic to Afghanistan. Schizostegia is based on A. schizostegium Rech.f. \& Schiman-Czeika, Poicilocephala on A. glutinosum Rech.f. \& Köie and Stereophylla on A. stereophyllum Rech.f.\& Schiman-Czeika. These three species are represented in our study and fell in the unresolved region of clade $\mathrm{B} 2$ that contains representatives of nine of the accepted sections (Fig. 2A). Therefore, not much can be concluded about their affinities.

\section{Section Physostegia}

This is a monotypic section, based on A. physostegium Rech.f. \& Schiman-Czeika (Rechinger \& SchimanCzeika, 1974), endemic to Afghanistan. In our study, A. physostegium is sister to a subclade in clade B2 formed by A. solidum Rech.f. \& Köie and A. tricolor Rech.f. \& Köie, both from section Acantholimon and endemic to Afghanistan although with weak support (Fig. 2B). This questions either the independence of this section or the monophyly of section Acantholimon.

\section{Section Acantholimon (= section Staticopsis)}

As currently defined, this is the largest and most diverse section in the genus, consisting of up to 135 species (Rechinger \& Schiman-Czeika, 1974; Assadi, 2005; Doğan \& Akaydin, 2007), of which 57 were analysed in this study. It is also the most widespread, spanning the whole range of the genus, and can be recognized by the following set of morphological characters: spikelike inflorescences (simple or branched), one-flowered two-bracteate spikelets and an infundibular calyx, glabrous within. However, as currently circumscribed, this section is polyphyletic since the species sampled fell into nine positions in clades A and B (Fig. 2). Of the resulting subclades in which section Acantholimon is represented, there are four that suggest natural groupings, although some would require small changes in the allocation of species to sections. For instance, 17 mostly Iranian species form a monophyletic group, although with weak support in clade A3 (A. aspadanum Bunge to A. scabrellum Boiss. \& Hausskn. ex Boiss. in Fig. 2C). Among those that would require some changes to form monophyletic groups are 11 species that fell in a structured subclade also in clade A3 with three species of section Armeriopsis (A. bracteatum, type of the section, A. bromifolium Boiss. ex Bunge and A. latifolium Boiss.) (Fig. 2C). If these results are confirmed by future studies, all the species in A3, from sections Armeriopsis and Acantholimon, could be merged into a single section. A close relationship between these sections was suggested based on the phenetic study of Doğan et al. (2007) although they formed two distinct clusters. Another example of a potential natural group to be identified in future studies is the case of 12 species that formed a monophyletic group in clade B2 with low support (A. sackenii Bunge to A. alatavicum Bunge in Fig. 2B) although only with the inclusion of one species from section Glumaria, A. ekatherinae (B.Fedtsch.) Czerniak. Furthermore, in that same clade, three smaller geographically coherent clades can be identified: one clade formed by five species of section Acantholimon (A. aulieatense Czerniak., A. knorringianum Lincz., A. laxum Czerniak., A. nabievii Lincz. and $A$. sackenii) with A. ekatherinae (section Glumaria) from Central Asia; a second clade formed by two species from Iran (A. fomini Kusn. and A. mishaudaghense Mobayen); and a third clade including two species from Turkey (A. hypochaerum Mobayen and A. wiedemanii Bunge). Finally, six species from section Acantholimon (A. avenaceum Bunge, A. blandum Czernjak., A. bodeanum Bunge, A. flabellum Assadi, A. gorganense Mobayen and $A$. raddeanum Czernjak.) and $A$. scirpinum Bunge (section Glumaria) formed a strongly supported but unresolved subclade in clade B2 (Fig. 2A). Accessions of $A$. festucaceum were scattered across four positions in clade A3, a pattern that should be studied with an extended sampling and may suggest the occurrence of different entities and/or hybridization. Double peaks were detected in nrDNA ITS sequences in two samples, which were discarded.

\section{Section Armeriopsis}

This is also a large section of up to 35 species (Linczevski, 1967; Rechinger \& Schiman-Czeika, 1974; Assadi, 2005; Doğan \& Akaydin, 2007), of which 18 have been sampled in this study. Its main centre of diversity is located in Iran and Afghanistan and it is diagnosed by the capitate inflorescences made of condensed spikes with two- to five-flowered, two- to six-bracteate spikelets and an infundibular calyx, glabrous within. The phylogenetic results suggest that, as presently circumscribed, the section does not represent a monophyletic group. The sampled species fell into different placements in clades A and B (Fig. 2). The most strongly supported group in the section is composed of six species that fall in clade A3. Two (A. cephalotoides Rech.f. and A. demavendicum Bornm.) from Iran form a group that is sister to a clade formed by four species (A. diapensioides Boiss., A. ekbergianum Rech.f. \& Schiman-Czeika, A. cephalotes Boiss. and A. compactum Korovin) from Afghanistan and Pamir (Fig. 2C). As discussed above, the monophyletic group A3, gathering species from 
sections Acantholimon and Armeriopsis, may deserve taxonomic recognition. The rest of the species of section Armeriopsis appeared intermingled with representatives of sections Acantholimon, Acmostegia, Glumaria, Microstegia and Tragacanthina in clade B2 (Fig. 2A, B).

\section{Section Glumaria}

This section, comprising up to 30 species distributed in Central Asia, Iran and Afghanistan (Linczevski, 1967; Rechinger \& Schiman-Czeika, 1974; Assadi, 2005), is shown to be an artificial group. It is defined morphologically by its dimorphic leaves, lax spike-like inflorescences, one- to three-flowered, two- to six-bracteate spikelets and an infundibular calyx, glabrous within. Not only are the nine species analysed here dispersed across clade B2, but also no clade exclusively integrated by species of this section emerged from our analyses (Fig. 2A, B).

\section{Section Microstegia (= Dracogina Mobayen)}

The six species of this small (seven species) morphologically uniform Iranian section sampled here fell in two different positions in clade B2 with A. austroiranicum Rech.f. \& Schiman-Czeika separated from the five remaining species (Fig. 2A, B). Therefore, our study suggests that the set of morphological features used to define the section, including dimorphic leaves, capitate inflorescences made of condensed spikes, one- to four-flowered, two- to four-bracteate spikelets and an infundibular calyx, pilose within, have evolved in parallel at least twice.

\section{Section Tragacanthina}

This large section comprises up to 25 species, distributed across Iran, Afghanistan, eastern Turkey, Caucasus and Central Asia (Linczevski, 1967; Rechinger \& Schiman-Czeika, 1974; Assadi, 2005; Doğan \& Akaydin, 2007). The set of characters used to define it is far from unique (heteromorphic leaves, lax or dense paniculate inflorescences, one-flowered, three-bracteate spikelets and a tubular or infundibular calyx, glabrous within). Thus, it is not unexpected that it represents another artificial assemblage. The 17 species sampled fell into four different positions in clade B2 and no smaller monophyletic groups were recovered except for the one including A. leucacanthum Boiss. and A. curviflorum Bunge, which, however, received weak support (Fig. 2A, B).

\section{EVOLUTION OF MORPHOLOGICAL CHARACTERS AND THE ORIGIN OF THE ACANTHOLIMON SYNDROME}

A direct consequence of the poor fit of the current infrageneric taxonomy of Acantholimon to the phylogenetic results provided here is that some of the morphological characters seem to be of limited use in defining monophyletic groups. The maximum likelihood approach to study the evolution of a selection of those morphological characters indicates that they convey varying levels of homoplasy. Nevertheless, the morphological patterns identified in this study pose questions that seem to be closely linked to the origin and diversification of the lineages identified in the phylogenetic analyses.

Of the four characters surveyed, two (number of flowers per spikelet and calyx shape) have been mainly used to diagnose sections in combination with others, whereas the other two (habit and leaves) have been mainly used to diagnose genera. Calyx shape and number of flowers per spikelet were inferred to change repeatedly along Acantholimon s.l., illustrating their limited use for identifying infrageneric groups (Fig. 4; Supporting Information, Fig. S4). However, calyx shape shows more consistency, compared to number of flowers per spikelet, with the phylogenetic trees (e.g. clade A has an exclusively infundibular calyx, except for the Vassilczenkoa + Chaetolimon clade) and the existing classifications (e.g. the large sections Acantholimon and Armeriopsis have an infundibular calyx).

Habit and leaves have three aspects in common: they show less homoplasy arising once or twice in Acantholimon s.l. (with a probable reversal of the acuminate rigid leaves towards unarmed soft leaves in section Inermia), there is some correlation between the two (Fig. 3) and they have been important in the taxonomic recognition of the ACRG. The ancestral character state reconstruction for these two characters illustrates how most of the ACRG have been considered independent genera because they depart from what we here call the 'Acantholimon syndrome', that is, a pulvinate to densely branched-caespitose subshrub with linear rigid acuminate leaves (Fig. 5). Specifically, such a departure from the Acantholimon syndrome can be represented by two morphological schemes in seven of the eight ACRG sampled (Fig. 3). Five of these (Bamiania, Bukiniczia, Cephalorhizum, Dictyolimon and Popoviolimon) conform to a scheme (referred to here as the 'Limonium syndrome') that is quite common in Limonioideae not only in most Limonium spp., but also in Goniolimon. The Limonium syndrome is characterized by the perennial herbaceous habit, paniculate inflorescences, a poorly to moderately branched thick rootstock and rosulate leaves, which are somehow spathulate, slightly fleshy and leathery when dry. Chaetolimon and Vassilczenkoa represent a different morphological pattern. They have been assigned character state 1 for habit based on their rosulate leaf arrangement. However, their caespitose habit, together with their leaves, which are soft, sublinear or linear-oblanceolate, with a non-rigid apical bristle, suggest a different scheme with respect to the Limonium syndrome. This pattern in Chaetolimon and Vassilczenkoa is much more taxonomically restricted 

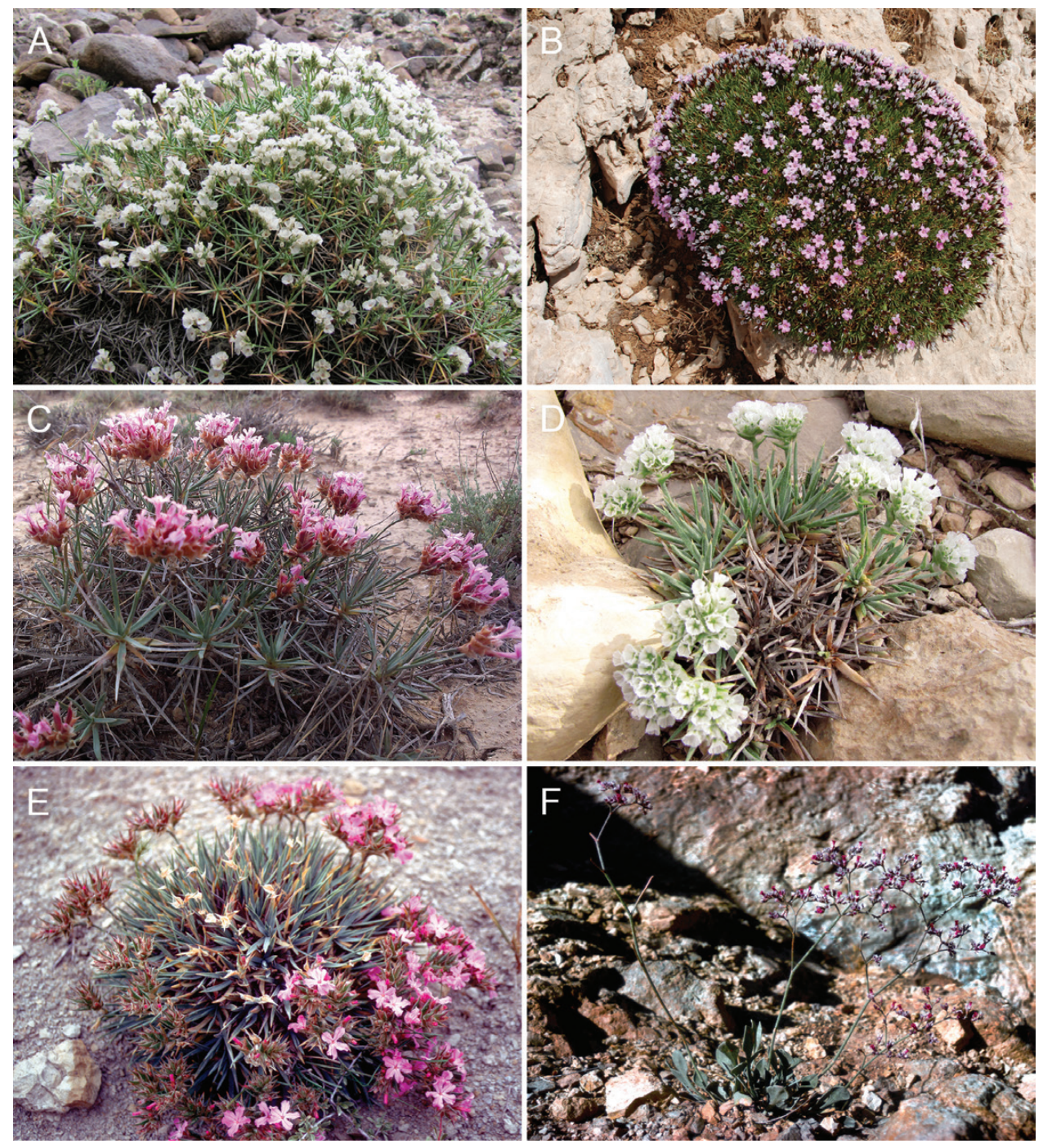

Figure 5. Morphological syndromes in Acantholimon and closely related genera. Acantholimon syndrome (pulvinate to densely branched-caespitose subshrub with linear acuminate leaves) in: A, A. talagonicum Boiss.; B, A. libanoticum Boiss.; C, A. acmostegium Boiss. \& Buhse; D, A. pterostegium Bunge; E, A. speciosissimum Aitch. \& Hemsl. [Gladiolimon speciosissimum (Aitch. \& Hemsl.) Mobayen]. Limonium syndrome (perennial herb with paniculate inflorescence, moderately branched rootstock and rosulate spathulate leaves, slightly fleshy, leathery when dry) in F, Bamiania pachycorma (Rech.f.) Lincz. Photograph credits: A, Shahrokh Kazempour-Osaloo; B, Magda Bou Dagher; C-D, Robabeh Shahi; E-F, Ian C. Hedge CCollections of the Royal Botanic Garden Edinburgh.

(three species) than the Limonium and Acantholimon syndromes and seems to be associated with more developed soils at lower elevations in the mountains. In contrast, the eighth of these genera, Gladiolimon, conforms to the Acantholimon syndrome and fell in Acantholimon s.s. in the molecular phylogenetic trees (Fig. 2).

Two hypotheses could explain the occurrence of the two main morphological syndromes in Acantholimon s.l. In the first, the crown node of the Acantholimon s.l. conformed to the Limonium syndrome. This would imply convergence in the Acantholimon syndrome, i.e. independent origins in clades $\mathrm{A}$ and $\mathrm{B}$, and two reversals to the leaf character state 2 in clade A1 (Chaetolimon + Vassilczenkoa) and in section Inermia (B2, Figs 2, 3 ). The second hypothesis is that the crown node of Acantholimon s.l. conformed to the Acantholimon syndrome so that the pulvinate to densely branchedcaespitose subshrub with linear acuminate leaves originated once. This hypothesis requires a parallel reversal to the Limonium syndrome in Bamiania, Cephalorhizum and Popoviolimon (in clade A) and Bukiniczia and Dictyolimon (in clade B) and reversals to the leaf character state 2 in clade A1 (Chaetolimon + Vassilczenkoa) and section Inermia (clade B2). 
Based on the higher likelihood that the character states for habit and leaves in the Acantholimon s.l. crown node were 2 and 3, respectively (Supporting Information, Appendix S2, Fig. 3), the second hypothesis would be more likely than the first; however, the second is less parsimonious. In addition, since the Limonium syndrome is common among Limonioideae and occurs specifically in the sister group, Goniolimon, it is also conceivable that the character states that define it ( 1 for both habit and leaves) have been retained as plesiomorphic in Acantholimon s.l., specifically in Bamiania, Bukiniczia, Cephalorhizum, Dictyolimon and Popoviolimon, and the Acantholimon syndrome originated twice. An independent acquisition of the Acantholimon syndrome is conceivable considering that characters such as the rigid acuminate leaves - offering comparatively reduced water loss and protection against herbivory - and the cushion (or densely caespitose subshrubby) habit are not uncommon in open continental mountainous dry habitats with poorly developed soils (Boucher et al., 2016). In fact, a similar habit occurs in a different genus of Caryophyllales, Acanthophyllum C.A.Mey. (Pirani et al., 2014; Manafzadeh et al., 2014; Hernández-Ledesma et al., 2016), also distributed in the Irano-Turanian region.

The Limonium syndrome displayed in Bamiania, Bukiniczia, Cephalorhizum, Dictyolimon and Popoviolimon occurs in similar habitats to those in which Acantholimon s.s. species occur and leaves in these genera show thicker epidermis and higher imbrication in the rosettes, particularly Bukiniczia and Dictyolimon, compared with, for example, Goniolimon (Fig. 5F). Thus, no matter if the Limonium syndrome in Acantholimon s.l. represents a retained plesiomorphic condition (first hypothesis) or resulted from a parallel reversal (second hypothesis), it appears that it required specific adaptations to those habitats in parallel with the Acantholimon syndrome. The reconstruction of ancestral morphological character states against the molecular phylogenetic trees raises interesting questions such as whether the unique or convergent acquisition of the Acantholimon syndrome influenced the species richness and whether a burst of diversification took place in this lineage. Both questions are being addressed in an ongoing study.

\section{ACKNOWLEDGEMENTS}

We are grateful to Ricarda Riina, Carlos García Verdugo and an anonymous reviewer for helpful comments on the manuscript, to Isabel Sanmartín for methodological advise, to Werner Greuter for nomenclatural advice, to Karol Marhold for translation of labels in Russian, to Alberto Herrero for his help in the lab, to Carlos de Mier for his assistance in preparing Fig. 5, to Magda Bou Dagher and Ian C. Hedge for permission to publish their photographs and to the curators of the herbaria cited in Appendix S1 and Juli Caujapé, Charo Noya, Robabeh Shahi and Hajar Hassanpour for loans and/or providing samples of rare and not easily accessible material. Special thanks are given to Ernst Vitek, Allan Forrest and Andreas Fleischmann for their significant support in obtaining samples. Financial support was received from the research council of the Tarbiat Modares University through a PhD student fellowship to F.M.; IAPT, through a research improvement grant to F.M.; and the Spanish Ministry of Economy and Competitivity, through grant CGL2013-49097-C2-1-P to G.N.F..

\section{REFERENCES}

Álvarez I, Wendel JF. 2003. Ribosomal ITS sequences and plant phylogenetic inference. Molecular Phylogenetics and Evolution 29: 417-434.

Assadi M. 2005. Plumbaginaceae. In: Assadi M, Jamzad Z, Maassoumi AA, eds. Flora of Iran, Vol 51. Tehran: Research Institute of Forests and Rangelands (RIFR), 47-204.

Assadi M. 2006. Distribution patterns of the genus Acantholimon (Plumbaginaceae) in Iran. Iranian Journal of Botany 12: 114-120.

Baeza AJ. 2016. Molecular phylogeny of porcelain crabs (Porcellanidae: Petrolisthes and allies) from the south eastern Pacific: the genera Allopetrolisthes and Liopetrolisthes are not natural entities. PeerJ 4: e1805.

Boissier E. 1846. Diagnoses plantarum orientalium novarum. Ser. 1, Vol. 1, Part 7. Leipzig, 69.

Bokhari MH, Edmondson JR. 1982. Acantholimon Boiss. In: Davis PH, ed. Flora of Turkey and the East Aegean Islands, Vol. 7. Edinburgh: Edinburgh University Press, 478-502.

Boucher FC, Lavergne S, Basile M, Choler P, Aubert S. 2016. Evolution and biogeography of the cushion life form in angiosperms. Perspectives in Plant Ecology, Evolution and Systematics 20: 22-31.

Bunge Av. 1872. Die Gattung Acantholimon Boiss. Mémoires de l'Academie Impériale des Sciences de Saint Pétersbourg, Sér. 7: 1-72.

Chase MW, Soltis DE, Olmstead RG, Morgan D, Les DH, Mishler BD, Duvall MR, Price RA, Hills HG, Qiu YL, Kron KA, Rettig JH, Conti E, Palmer JD, Manhart JR, Sytsma KJ, Michael HJ, Kress WJ, Karol KG, Clark WD, Hedren M, Gaut BS, Jansen RK, Kim YJ, Wimpee CF, Smith JF, Furnier GR, Strauss SH, Xiang QY, Plunkett GM, Soltis PS, Swensen SM, Williams SE, Gadek PA, Quinn CJ, Eguiarte LE, Golenberg E, Learn GH Jr, Graham SW, Barrett SCH, Dayanandan S, Albert VA. 1993. DNA sequence phylogenetics of seed plants: an analysis of the plastid gene rbcL. Annals of the Missouri Botanical Garden 80: 528-580.

Doğan M,Akaydin G. 2007. Synopsis of Turkish Acantholimon Boiss. (Plumbaginaceae). Botanical Journal of the Linnean Society 154: 397-419.

Doğan M, Akaydin G, Çakarogullari D. 2007. Infrageneric grouping of Turkish Acantholimon Boiss. (Plumbaginaceae) assessed by numerical taxonomy. Advances in Biological Research 1: 85-91. 
Doğan HM, Doğan M, Akaydin G, Celep F. 2011. Mapping and analysing the diversity of the genus Acantholimon taxa in Turkey by geographic information systems (GIS). Turkish Journal of Botany 35: 91-110.

Doyle JJ, Doyle JL. 1987. A rapid DNA isolation procedure for small quantities of fresh leaf tissue. Phytochemical Bulletin, Botanical Society of America 19: 11-15.

Edgar RC. 2004. MUSCLE: multiple sequence alignment with high accuracy and high throughput. Nucleic Acids Research 32: 1792-1797.

Felsenstein J. 1985. Confidence limits on phylogenies: an approach using the bootstrap. Evolution 39: 783-791.

Fuertes Aguilar J, Rosselló JA, Nieto Feliner G. 1999. Molecular evidence for the compilospecies model of reticulate evolution in Armeria (Plumbaginaceae). Systematic Biology 48: 735-754.

Hall TA. 1999. BioEdit: a user friendly biological sequence alignment editor and analysis program for Windows 95/98/ NT. Nucleic Acids Symposium Series 41: 95-98.

Hernández-Ledesma P, Berendsohn WG, Borsch T, Von Mering S, Fuentes-Bazan S, Korotkova N, HernandezLedesma P, Borsch T, Korotkova N, Akhani H, Arias S, Castaneda-Noa I, Eggli U, Eriksson R, Oxelman B, Flores-Olvera H, Ochoterena H, Kadereit G, Klak C, Nyffeler R, Ocampo G, Rabeler RK, Sanchez A, Schlumpberger BO, Uotila P. 2016. A taxonomic backbone for the global synthesis of species diversity in the angiosperm order Caryophyllales. Willdenowia 45: 281-383.

Kass RE, Raftery AE. 1995. Bayes factors. Journal of the American Statistical Association 90: 773-795.

Kubitzki K. 1993. Plumbaginaceae. In: Kubitzki K, Rohwer JG, Bittrich V, eds. The families and genera of vascular plants, Vol. 2. Berlin: Springer, 523-530.

Lartillot N, Philippe H. 2006. Computing Bayes factors using thermodynamic integration. Systematic Biology 55: 195-207.

Linczevski IA. 1967. Plumbaginaceae. In: Shishkin BK, Bobrov EG, eds. Flora of the USSR, Vol. 18, p. 216-348. Jerusalem/Washington: Israel Program for Scientific Translations/Smithsonian Institution and the National Science Foundation.

Linczevski IA. 1971. Notes on Limoniaceae. 3. Botanicheskiy Zhurnal 56: 1633-1635.

Linczevski IA. 1979. Notulae de Limoniaceis, 4. Novitates Systematicae Plantarum Vascularum 16: 166-168.

Linczevski IA. 1985. Notulae de Limoniaceis, 6. Novitates Systematicae Plantarum Vascularum 22: 200-207.

Lledó MD, Crespo MB, Cameron KM, Fay MF, Chase MW. 1998. Systematics of Plumbaginaceae based upon cladistic analysis of rbcL sequence data. Systematic Botany 23: 21-29.

Lledó MD, Crespo MB, Cox AV, Fay MF, Chase MW. 2000. Polyphyly of Limoniastrum (Plumbaginaceae): evidence from DNA sequences of plastid $r b c L$ and $\operatorname{trnL}$ intron and $\operatorname{trnL}-F$ intergenic spacer. Botanical Journal of the Linnean Society 132: 175-191.

Lledó MD, Karis PO, Crespo MB, Fay MF, Chase MW. 2001. Phylogenetic position and taxonomic status of the genus Aegialitis and subfamilies Staticoideae and Plumbaginoideae (Plumbaginaceae): evidence from plastid
DNA sequences and morphology. Plant Systematics and Evolution 229: 107-124.

Lledó MD, Erben M, Crespo MB. 2003. Myriolepis, a new genus segregated from Limonium (Plumbaginaceae). Taxon 52: $67-73$

Lledó MD, Crespo MB, Fay MF, Chase MW. 2005. Molecular phylogenetics of Limonium and related genera (Plumbaginaceae): biogeographical and systematic implications. American Journal of Botany 92: 1189-1198.

Lledó MD, Erben M, Crespo MB. 2005. Myriolimon, a new name for the recently published Myriolepis (Plumbaginaceae). Taxon 54: 811-812.

Manafzadeh S, Salvo G, Conti E. 2014. A tale of migrations from east to west: the Irano-Turanian floristic region as a source of Mediterranean xerophytes. Journal of Biogeography 41: 366-379.

Miller MA, Pfeiffer W, Schwartz T. 2010. Creating the CIPRES Science Gateway for inference of large phylogenetic trees. In Proceedings of the Gateway Computing Environments Workshop (GCE) 2010. New Orleans: Institute of Electrical and Electronics Engineers (IEEE), 1-8.

Mobayen S. 1964. Revision taxonomique du genre Acantholimon. D. Phil. Thesis, Université de Montpellier, France.

Moharrek F, Kazempour-Osaloo S,Assadi M. 2014. Molecular phylogeny of Plumbaginaceae with emphasis on Acantholimon Boiss. based on nuclear and plastid DNA sequences in Iran. Biochemical Systematics and Ecology 57: 117-127.

Moore DM. 1972. Acantholimon. In: Tutin TG, Heywood V, Burges NA, Moore DM, Valentine DH, Walters SM \& Webb DA, eds. Flora Europaea, Vol. 3. Cambridge: Cambridge University Press, 30.

Nieto Feliner G, Rosselló JA. 2007. Better the devil you know? Guidelines for insightful utilization of nrDNA ITS in species-level evolutionary studies in plants. Molecular Phylogenetics and Evolution 44: 911-919.

Nylander JAA. 2004. MrModeltest, version 2. Program distributed by the author. Evolutionary Biology Centre, Uppsala University. Available at: http://www.abc.se/ nylander/ mrmodeltest $2 /$ mrmodeltest2.html

Nylander JA, Ronquist F, Huelsenbeck JP, Nieves-Aldrey JL. 2004. Bayesian phylogenetic analysis of combined data. Systematic Biology 53: 47-67.

Nylander JA, Wilgenbusch JC, Warren DL, Swofford DL. 2008. AWTY (are we there yet?): a system for graphical exploration of MCMC convergence in Bayesian phylogenetics. Bioinformatics 24: 581-583.

Oganesian ME. 2011. Genus Acantholimon Boiss. (Plumbaginaceae) in south Transcaucasia (Armenia, Nakhichevan). Takhtajania 1: 51-59.

Page DM. 2001. Treeview (Win32) version 1.6.6. Available at: http://taxonomy.zoology.gla.ac.uk/rod/treeview.html

Pagel M. 1994. Detecting correlated evolution on phylogenies: a general method for the comparative analysis of discrete characters. Proceedings of the Royal Society of London B: Biological Sciences 255: 37-45.

Paradis E, Claude J, Strimmer K. 2004. APE: Analyses of phylogenetics and evolution in $\mathrm{R}$ language. Bioinformatics 20: $289-290$. 
Peng Z-X, Kamelin RV. 1996. Plumbaginaceae. In Wu ZY, Raven PH, eds. Flora of China, Vol. 15. St. Louis: Missouri Botanical Garden Press, 190-204.

Pirani A, Zarre S, Bernard E, Pfeil BE, Yann JK, Bertrand YJK, Assadi M, Oxelman B. 2014. Molecular phylogeny of Acanthophyllum (Caryophyllaceae: Caryophylleae), with emphasis on infrageneric classification. Taxon 63: 592-607.

Posada D, Buckley TR. 2004. Model selection and model averaging in phylogenetics: advantages of Akaike information criterion and Bayesian approaches over likelihood ratio tests. Systematic Biology 53: 793-808.

R Development Core Team. 2010. $R$ : a language and environment for statistical computing. Vienna: R Foundation for Statistical Computing.

Rambaut A, Drummond AJ. 2007. Tracer, version 1.4. Computer program and documentation distributed by the author. Available at: http://tree.bio.ed.ac.uk/software/tracer/

Rechinger KH, Schiman-Czeika H. 1974. Plumbaginaceae In: Rechinger KH, ed. Flora Iranica, Vol 108. Graz: Akademische Druck-u, 1-158.

Reveal JL. 2012. Newly required infrafamilial names mandated by changes in the Code of Nomenclature for Algae, Fungi, and Plants. Phytoneuron 33: 1-32.

Ronquist F, Huelsenbeck JP, van der Mark P. 2005. MrBayes 3.1 Manual, Draft 5/26/2005. Available at: http:// mrbayes.csit.fsu.edu/manual.php

Ronquist F, Teslenko M, van der Mark P, Ayres DL, Darling A, Höhna S, Larget B, Liu L, Suchard MA, Huelsenbeck JP. 2012. MrBayes 3.2: efficient Bayesian phylogenetic inference and model choice across a large model space. Systematic Biology 61: 539-542.

Sang T, Crawford DJ, Stuessy T. 1995. Documentation of reticulate evolution in peonies (Paeonia) using internal transcribed spacer sequences of nuclear ribosomal DNA: implication for biogeography and concerted evolution. Proceedings of the National Academy of Sciences USA 92: 6813-6817.

Shaw J, Lickey EB, Beck JT, Farmer SB, Liu W, Miller J, Siripun KC, Winder CT, Schilling EE, Small RL. 2005. The tortoise and the hare II: relative utility of 21 noncoding chloroplast DNA sequences for phylogenetic analysis. American Journal of Botany 92: 142-166.

Silvestro D, Michalak I. 2012. raxmlGUI: a graphical front-end for RAxML. Organisms Diversity and Evolution 12: 335-337.

Swofford DL. 2002. PAUP*: phylogenetic analysis using parsimony (*and other methods), version 4.0 Beta. Sunderland: Sinauer Associates.

Tamura K, Peterson D, Peterson N, Stecher G, Nei M, Kumar S. 2011. MEGA5: molecular evolutionary genetics analysis using maximum likelihood, evolutionary distance, and maximum parsimony methods. Molecular Biology and Evolution 28: 2731-2739.

White TJ, Bruns T, Lee S, Taylor J. 1990. Amplification and direct sequencing of fungal ribosomal RNA genes for phylogenetics. In: Innis M, Gelfand D, Sninsky J, White T, eds. PCR protocols: a guide to methods and applications. San Diego: Academic Press, 315-322.

Yildirim H, Crespo MB. 2014. Acantholimon riyatguelii (Plumbaginaceae), a threatened new unarmed species from central Anatolia, Turkey. Phytotaxa 175: 73-84.

\section{SUPPORTING INFORMATION}

Additional Supporting Information may be found in the online version of this article at the publisher's web-site:

Appendix S1. Voucher information: species name, locality, collector(s), voucher (herbarium), GenBank accession numbers for nrDNA ITS and trnY-T, respectively (*sequences new for this study).

Appendix S2. Morphological characters selected for this study and character states coding.

Appendix S3. Model testing (equal-rates model - ER; symmetrical model - SYM; all-rates-different model - ARD) for ancestral character state reconstruction under a maximum likelihood approach using likelihood ratio test (LRT). Table S1. Morphological characters and states for each species.

Figure S1. Maximum likelihood cladogram of the combined nrDNA ITS and $\operatorname{trn} Y$ - $T$ datasets, generated by raxmlGUI used for the character evolution analyses. Bootstrap values $\geq 50$ are indicated.

Figure S2. Bayesian 50\% majority rule consensus tree of Acantholimon and closely related genera (Bamiania, Bukiniczia, Chaetolimon, Cephalorhizum, Dictyolimon, Gladiolimon, Popoviolimon, Vassilczenkoa) based on the nrDNA ITS region. Nodes with Bayesian posterior probability (PP), maximum likelihood bootstrap (ML BS) and maximum parsimony bootstrap (MP BS) values $\geq 50 \%$ are indicated.

Figure S3. Bayesian 50\% majority rule consensus tree of Acantholimon and closely related genera (Bamiania, Bukiniczia, Chaetolimon, Cephalorhizum, Dictyolimon, Gladiolimon, Popoviolimon, Vassilczenkoa) based on the $\operatorname{trnY} Y$-T region. Bayesian posterior probability (PP), maximum likelihood bootstrap (ML BS) and maximum parsimony bootstrap (MP BS) $\geq 50 \%$ are shown in the nodes.

Figure S4. Morphological character evolution of the number of flowers per spikelet [one vs. (one) two to five] optimized on a maximum likelihood tree obtained from a combined (nrDNA ITS and $\operatorname{trn} Y-T$ ) molecular dataset with one sample per species. 